\title{
Irbesartan inhibits metastasis by interrupting the adherence of tumor cell to endothelial cell induced by angiotensin II in hepatocellular carcinoma
}

\author{
Long-Hai Feng ${ }^{1,2 \#}$, Hui-Chuan Sun ${ }^{1,2 \#}$, Xiao-Dong Zhu ${ }^{1,2}$, Shi-Zhe Zhang ${ }^{1,2}$, Xiao-Long Li $^{1,2}$, Kang-Shuai Li $^{1,2}$, \\ Xue-Feng Liu ${ }^{1,2}$, Ming Lei ${ }^{1,2}$, Yan $\mathrm{Li}^{1,2}$, Zhao-You Tang ${ }^{1,2}$ \\ ${ }^{1}$ Department of Liver Surgery and Transplantation, Liver Cancer Institute and Zhongshan Hospital, Fudan University, Shanghai, China; ${ }^{2}$ Key \\ Laboratory of Carcinogenesis and Cancer Invasion of Ministry of Education, Shanghai, China \\ Contributions: (I) Conception and design: LH Feng, HC Sun, XD Zhu, ZY Tang; (II) Administrative support: HC Sun, XD Zhu, ZY Tang; (III) \\ Provision of study materials or patients: HC Sun, XD Zhu, XL Li, ZY Tang; (IV) Collection and assembly of data: LH Feng, SZ Zhang, XL Li, KS \\ Li, XF Liu, M Lei, Y Li; (V) Data analysis and interpretation: LH Feng, SZ Zhang, XL Li, KS Li, XF Liu, M Lei, Y Li; (VI) Manuscript writing: All \\ authors; (VII) Final approval of manuscript: All authors. \\ \#These authors contributed equally to this work. \\ Correspondence to: Zhao-You Tang. Department of Liver Surgery and Transplantation, Liver Cancer Institute and Zhongshan Hospital, Fudan \\ University, Shanghai, China. Email: zytang88@163.com.
}

\begin{abstract}
Background: The use of angiotensin II inhibitors is associated with a low risk of recurrence and metastasis in hepatocellular carcinoma (HCC) patients. Vascular cell adhesion molecule-1 (VCAM-1) is a key factor in tumor metastasis.

Methods: The effects of angiotensin II and irbesartan (an angiotensin II inhibitor) on HCC were explored with a xenograft model, microarray analysis and cell adhesion experiments. The relationship between the expression of VCAM-1 in HCC tissues and prognosis was analyzed with public and our institutional clinical databases. The effects of angiotensin II, irbesartan and VCAM-1 on adhesion and metastasis in HCC were explored with a xenograft model and cell adhesion experiments. The regulatory mechanisms were analyzed by Western blot analysis.
\end{abstract}

Results: Angiotensin II type 1 receptor and VCAM-1 were expressed in HCC tissues. Irbesartan inhibited HCC growth and metastasis in vivo and weakened the adhesion of HCC cells to endothelial cells, an effect that was enhanced by angiotensin II. VCAM-1 was found to be an independent risk factor for recurrence and survival in HCC patients with microvascular invasion. Angiotensin II upregulated VCAM-1 expression, and this upregulation was inhibited by irbesartan. Angiotensin II enhanced adhesion mainly by promoting the expression of VCAM-1 in HCC cells. Irbesartan inhibited the expression of VCAM-1 by reducing p38/ MAPK phosphorylation activated by angiotensin II in HCC cells.

Conclusions: Irbesartan attenuates metastasis by inhibiting angiotensin II-activated VCAM-1 via the p38/ MAPK pathway in HCC.

Keywords: Hepatocellular carcinoma (HCC); irbesartan; metastasis; vascular cell adhesion molecule-1 (VCAM-1)

Submitted Jul 18, 2020. Accepted for publication Nov 08, 2020.

doi: 10.21037/atm-20-5293

View this article at: http://dx.doi.org/10.21037/atm-20-5293 


\section{Introduction}

Hepatocellular carcinoma (HCC) is the most frequently occurring primary liver cancer and the third leading cause of cancer-related death worldwide $(1,2)$. The global estimated morbidity and related mortality rates continue to increase (3-5). Despite the tremendous progress achieved in the diagnosis and treatment of HCC, the overall efficacy remains unsatisfactory due to the high risk of recurrence and metastasis for patients undergoing curative therapy and the lack of effective drugs to target these phenomena $(6,7)$.

Currently, accumulating evidence shows that angiotensin II (Ang II) inhibitors, which are common antihypertensive drugs, can provide survival benefits to cancer patients (8-10). These drugs can attenuate cancer progression promoted by Ang II, which promotes tumor growth or exacerbates tumor invasion and metastasis by mediating angiogenesis, inflammation and immunosuppressive microenvironments (11-13).

Ang II has been shown to promote the growth of HCC, epithelial-mesenchymal transition, and angiogenesis and mediate the inflammatory microenvironment via angiotensin II type 1 receptor (AGTR-1) (14-17). An increasing (6 clinical reports) supporting studies have confirmed that Ang II inhibitors can improve the prognosis of HCC patients by enhancing the efficacy of sorafenib, reducing the risk of recurrence and prolonging survival after curative treatments (10,18-22). We also reported that the use of Ang II inhibitors was associated with a reduced risk of disease recurrence, prolonged survival and a decreased rate of extrahepatic metastases in HCC patients after curative resection (23).

HCC is a cancer with typical hematogenous metastasis. Microvascular invasion (MVI) and circulating tumor cells (CTCs) are direct evidence of hematogenous metastasis and the main cause of metastasis $(24,25)$. The adhesion of tumor cells to endothelial cells is a key step in tumor metastasis, and adhesion molecules play an important role in this process (26). Reports have indicated that Ang II can upregulate the expression of P-selectin, E-selectin and other adhesion molecules in endothelial cells to promote tumor cell adhesion, leading to the acceleration of tumor metastasis, and these molecules can be blocked by Ang II inhibitors $(11,13)$. Hence, we speculated whether Ang II could also promote HCC metastasis in this way and, if so, whether this effect could be blocked by Ang II inhibitors.

In the present study, we found that irbesartan (an Ang II inhibitor and an AGTR-1 blocker) attenuated metastasis by inhibiting the adhesion of HCC cells to endothelial cells enhanced by Ang II. Additionally, we found that irbesartan mainly reduced vascular cell adhesion molecule-1 (VCAM-1), which was promoted by Ang II via the p38/MAPK pathway in HCC cells to weaken this adhesion. We present the following article in accordance with the ARRIVE Checklist (available at http://dx.doi.org/10.21037/atm-20-5293).

\section{Methods}

\section{Cell cultures}

Human HCC cell lines (HCCLM3, HMHCC97-H, HMHCC97-L, SMMC-7721, Huh-7, Hep-3B and PLC), a hepatocyte cell line (L02) and human umbilical vein endothelial cells (HUVECs) were all obtained from the Liver Cancer Institute, Fudan University, Shanghai, China, and were cultured at $37{ }^{\circ} \mathrm{C}$ and $5 \% \mathrm{CO}_{2}$. The HCC and hepatocyte cells were cultured in Dulbecco's modified Eagle's medium (DMEM; HyClone, Logan, Utah, USA) containing $10 \%$ fetal bovine serum (FBS; HyClone) and $1 \%$ penicillin-streptomycin (PS; HyClone); HUVECs were cultured in endothelial cell medium (ECM; ScienCell, San Diego, California, USA) with $10 \%$ FBS, $1 \%$ PS and $1 \%$ endothelial cell growth supplement (ScienCell). It was approved by the Clinical Research Ethics Committee of Zhongshan Hospital, Fudan University, Shanghai, China (Approval No. B2012-010) and the individual consent for this retrospective analysis was waived.

\section{Overexpression of AGTR-1 and knockdown of VCAM-1 by transfection}

H-AGTR-1-OE (overexpression of AGTR-1), H-VCAM1-sh (knockdown of VCAM-1) and a vector control lentivirus were designed and constructed by Genomeditech (Shanghai, China). The cells $\left(2 \times 10^{5}\right)$ were seeded in each well of a six-well plate the day before transfection. Subsequently, the lentiviruses were added to the well with $2 \mathrm{~mL}$ of DMEM containing polybrene $(5 \mu \mathrm{g} / \mathrm{mL}$; Genomeditech) without FBS. Forty-eight hours later, the medium containing the lentivirus was removed and replaced with medium containing $10 \%$ FBS. The expression of AGTR-1 and VCAM-1 was assessed and validated by qPCR and Western blotting.

\section{Immunobistochemistry}

The UltraVision Quanto Detection HRP DAB System 
(Thermo Fisher Scientific, San Diego, California, USA) was used to perform immunohistochemical staining following the manufacturer's protocols to detect whether AGTR-1, angiotensin II type 2 receptor (AGTR-2) and VCAM-1 were expressed in HCC tissues and lung metastases. The antibodies against these three proteins were all purchased from Abcam (Cambridge, UK) and were diluted as follows: AGTR-1, 1:100; AGTR-2, 1:250; VCAM-1, 1:250.

\section{Western blotting}

Western blotting was performed following a standard procedure as described previously (27). The primary antibodies used included those against AGTR-1 (rabbit antibody; 1:1,000; Abcam), VCAM-1 (rabbit antibody; 1:2,000; Abcam), p38, p-p38, p65, p-p65, ERK, p-ERK, JNK and p-JNK (rabbit antibodies; 1:1,000; Cell Signaling Technology, Danvers, Massachusetts, USA). The loading control antibodies, GAPDH (rabbit antibody; 1:1,000) and $\alpha$-tubulin (rabbit antibody; 1:1,000), were purchased from BOSTER (Pleasanton, California, USA); the goat antirabbit $\operatorname{IgG}(1: 5,000)$ was from Yeasen (Shanghai, China).

\section{Quantitative real-time PCR assay}

RNA isolation from HCC cell lines and tissues and realtime PCR procedures were carried out according to the manufacturer's protocol (QuantStudio ${ }^{\mathrm{TM}} 3$, Thermo Fisher Scientific, San Diego, California, USA). The internal reference primer, GAPDH, was purchased from Sangon Biotech (Shanghai, China). The PCR primers and sequences are shown in Table S1.

\section{Human gene expression microarray}

Total RNA was extracted from SMMC-7721-AGTR1-OE, SMMC-7721-vector (control), Ang II-treatedHMHCC97-H, control-HMHCC97-H, Ang II-treated HCCLM3 and control-HCCLM3 cells and was analyzed by performing a human gene expression microarray (Agilent, Santa Clara, California, USA) from OE Biotech (Shanghai, China) to determine differential gene expression and biological behaviors.

\section{Cell adbesion assay}

The cell adhesion kit was purchased from KeyGEN BioTECH (Nanjing, Jiangsu, China), and the assay was performed according to the manufacturer's protocol. The bottom of the 96-well plate was plated with HUVECs, and $100 \mu \mathrm{L}$ of a single HCC cell suspension with $5 \times 10^{5}$ cells stained by calcein AM was added to the wells of a 96-well plate, which was then placed in the incubator for 30-120 minutes (depending on the attachment time of HCC cells). After incubation, the cell suspensions in the wells were removed and washed with $200 \mu \mathrm{L}$ of FBS-free DMEM 5 times to remove nonadhered HCC cells. PBS $(200 \mu \mathrm{L})$ was added to each well, after which the absorbance value was read (excitation wavelength $=494 \mathrm{~nm}$ ), from which the absorbance value of a blank control well was subtracted.

\section{Experiments on nude mice}

As described in our previous study, an orthotopic tumor xenograft model and a lung metastasis model were set up with 5-week-old male BALB/c nude mice (Weight =18-20 g) obtained from the Beijing Vital River Laboratory Animal Technologies Co., Ltd and maintained under specific pathogen-free conditions $(27,28)$. The animals were grouped randomly, and each group contained six mice. For the orthotopic tumor xenograft model, $200 \mu \mathrm{L}$ of the tumor cell suspension $\left(5.0 \times 10^{7}\right.$ cells $\left./ \mathrm{mL}\right)$ was injected subcutaneously, and when the tumor grew to $1.0 \mathrm{~cm}$ in diameter (approximately 4 weeks), it was cut into small nodules $\left(2.0 \times 2.0 \times 2.0 \mathrm{~mm}^{3}\right)$ and implanted into the liver. For the lung metastasis model, $150 \mu \mathrm{L}$ of the tumor cell suspension $\left(1.0 \times 10^{6}\right.$ cells $)$ was injected into nude mice through the tail vein. The groups and time axes of animal experiments are shown in Figures S1,S2. After the mice were euthanized, the size of the liver tumors and number of lung metastases were measured (27). The animal experiments were approved by the Shanghai Medical Experimental Animal Care Committee (Approval date, December 2017). All procedures were performed following the Guide for the Care and Use of Laboratory Animals and complied with institutional ethical guidelines.

\section{Drug dosage and mode of administration}

Ang II was administered by an ALZET osmotic pump (ALZA, Cupertino, California, USA; model: 1004; sustained release rate: $0.11 \mu \mathrm{L} /$ hour; duration: 4 weeks), which could release Ang II continuously, homogeneously and stably; avoid stress due to repeated administration; and protect the short half-life of the drug. Intragastric administration 
was used for irbesartan (trade name: Aprovel; Sanofi, Paris, France).

Referring to previous studies and the conversions of doses between humans and animals, we used a dose of Ang II (Sigma, St. Louis, Missouri, USA) of $100 \mathrm{ng} / \mathrm{kg} / \mathrm{min}$ for 4 weeks in nude mice and a dose of irbesartan (Aprovel) of $30 \mathrm{mg} / \mathrm{kg} /$ day $(13,29,30)$. For cytology experiments, Ang II (CSNpharm, Chicago, Illinois, USA) was used at $0.1 \mu \mathrm{M}$, irbesartan (CSNpharm) was used at $1 \mu \mathrm{M}$, PD123319 (Abcam) was used at $1 \mu \mathrm{M}$, and SB203580 (p38/MAPK signaling pathway inhibitor, Absin, Shanghai, China) was used at $10 \mu \mathrm{M}(14,15,31-35)$. When Ang II was combined with irbesartan, PD123319 or SB203580, the HCC cells were treated with these drugs for $0.5-2$ hours before the addition of Ang II to the medium.

\section{Tissue preparation from patients and follow-up}

The KM plotter public database and cases from our hospital were used for survival analysis (36). After excluding cases with recurrent HCC or combined hepatocellular cholangiocarcinoma or those with a medical history of hepatic or other malignant tumor resection and/ or perioperative mortality, 128 continuous HCC cases with MVI after curative resection were selected from the Department of Hepatology, Zhongshan Hospital, Fudan University, between January 2009 and December 2010. RNA from the HCC tissues was extracted from the frozen samples.

The data were extracted from medical records. The times to recurrence and overall survival were used as endpoint events. Follow-up and survival time calculations were performed as outlined in our previous report (23).

\section{Statistical analysis}

MedCalc software (version 18.2.1; Ostend, WestVlaanderen, Belgium) and $\mathrm{R}$ software (version 3.5.2) were used to analyze the data $(37,38)$. All statistical tests were 2-tailed and considered to be significantly different when $\mathrm{P}<0.05$. Continuous variables were analyzed with a $t$-test or a nonparametric test, and categorical variables were analyzed with the chi-square test, Fisher's exact test or the Wilcoxon signed-rank test, where appropriate. KaplanMeier and Cox proportional hazards regression analyses were used for survival. The optimal cutoff values of RNA expression of the adhesion factors were generated using $\mathrm{R}$ software with the survminer package (39).

\section{Results}

\section{Irbesartan weakened the adbesion of HCC cells enhanced by Ang II}

\section{Selection of the HMHCC97-H and HCCLM3 HCC cell lines as models based on their expression profiles of AGTR-1}

By immunohistochemical staining, we confirmed that AGTR-1 was expressed in human HCC tissues and that AGTR-2 was expressed weakly (Figure 1A). Next, the RNA and protein expression levels of AGTR-1 in commonly used HCC cell lines and the immortalized liver cell line L02 were analyzed (Figure 1B,C). The Hep-3B line had the highest expression level of AGTR-1, and the SMMC-7721 cell line had the lowest expression level of AGTR-1. The expression levels of AGTR-1 in the HMHCC97-H and HCCLM3 cell lines were relatively high. Considering the tumorigenic capacity of each HCC line in animals, the HMHCC97-H and HCCLM3 lines, which have highly aggressive and metastatic abilities, were finally selected as the main model cells in our study $(40,41)$.

\section{Irbesartan inhibited the growth and lung metastasis of HCC in vivo}

The HMHCC97-H cell line was used to perform orthotopic tumor xenograft experiments in nude mice, and the HCCLM3 line was used to perform lung metastasis experiments (Figure 2). The experimental animals were divided into 4 groups: control group, Ang II group, irbesartan group, and Ang II + irbesartan group ( $\mathrm{n}=6$ per group; no adverse events). The orthotopic tumor xenograft analysis indicated that the irbesartan group had the smallest tumor volume $\left(367.7 \pm 189.2 \mathrm{~mm}^{3}\right)$ and smallest number of lung metastases $\left(1.5 \pm 1.6 / \mathrm{cm}^{3}\right)$ and that the tumor volume in the Ang II group was the largest $\left(1,238.7 \pm 675.9 \mathrm{~mm}^{3}\right)$ with the highest number of lung metastases $\left(3.9 \pm 1.5 / \mathrm{cm}^{3}\right)$. Compared with that in the Ang II group, the tumor volume and lung metastases were significantly reduced in the Ang II + irbesartan group. Irbesartan significantly inhibited tumor growth $(\mathrm{P}<0.001)$ and reduced lung metastases from HCC $(\mathrm{P}=0.036)$. Lung metastasis analysis showed that the irbesartan group had the lowest tumor formation rate $(16.7 \%)$ and fewest lung metastases (average of $0.2 \pm 0.4$ ) and that the Ang II group had the highest formation rate of lung metastasis (100.0\%) and most lung metastases (average, $1.5 \pm 0.5$ ). Compared with the that of the control group, the average numbers of lung metastases in the Ang II group and irbesartan 

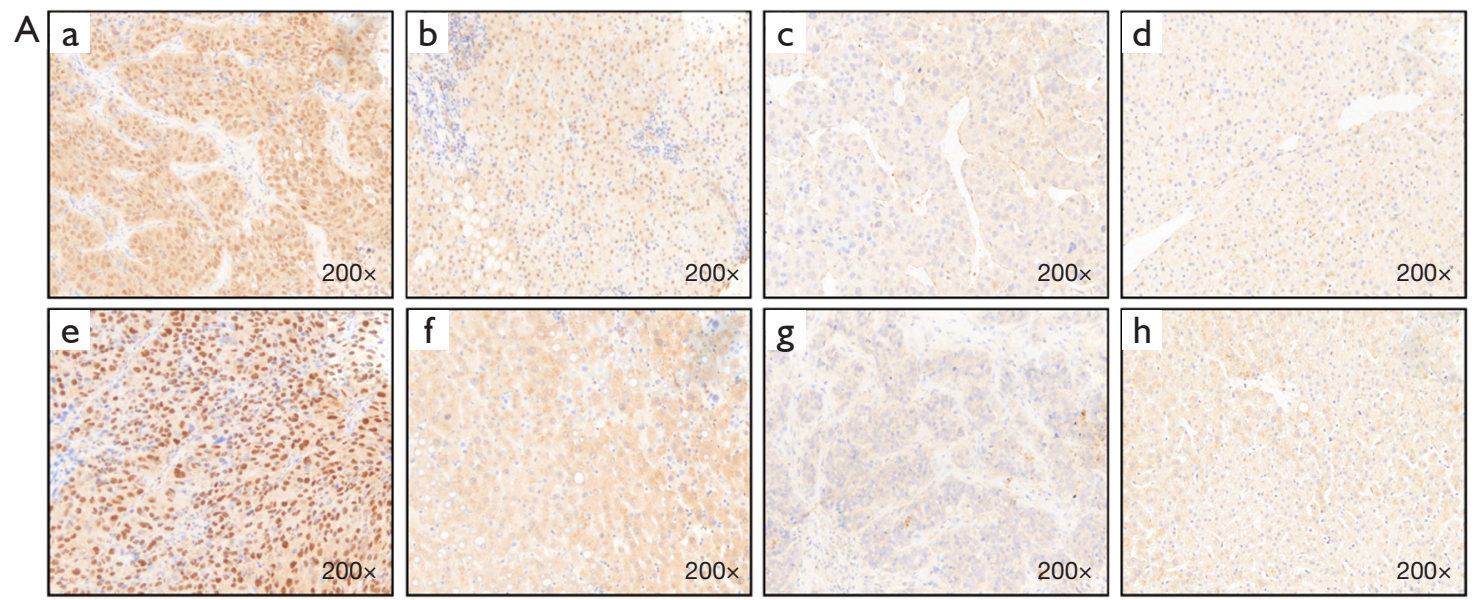

B
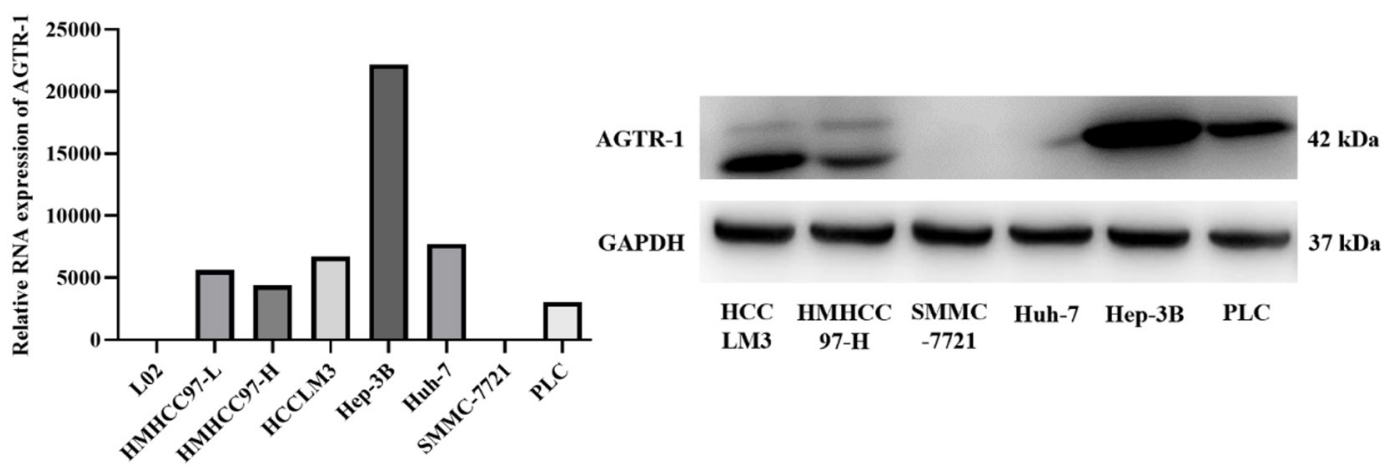

Figure 1 AGTR-1 was expressed in HCC tissues and HCC cell lines. (A) Immunohistochemistry staining of HCC and paired peritumoral tissues. AGTR-1 protein was expressed in HCC tissues on HCC cells (a and e) but weakly expressed in peritumoral tissue (b and f); AGTR-2 protein was expressed weakly on both HCC (c and $\mathrm{g}$ ) and paired peritumoral tissues ( $\mathrm{d}$ and h). (B) Real-time PCR and (C) Western blotting of AGTR-1 expression in HCC cell lines and a hepatocyte cell line (L02).

group were significantly different $(\mathrm{P}=0.038$ and $\mathrm{P}=0.018$, respectively). Compared with that in the Ang II group, the lung metastasis rate and number of lung metastases were reduced when Ang II was combined with irbesartan. These in vivo experiments further confirmed that Ang II could promote the growth and metastasis of HCC, which could be inhibited by irbesartan.

Human gene expression microarray confirmed that Ang II could affect the expression of adhesion molecules in HCC cells

RNA from SMMC-7721-AGTR-1-OE, Ang II-treatedHMHCC97-H, Ang II-treated HCCLM3 cells and the corresponding control HCC cells was analyzed with an Agilent human gene expression microarray. Compared with the respective control group, all three groups indicated that Ang II could affect the expression of adhesion molecules in HCC cells (Figure S3).
Irbesartan could inhibit the adhesion of HCC cells to endothelial cells enhanced by Ang II in vitro experiments

The HMHCC97-H and HCCLM3 HCC lines were used to perform cell adhesion experiments. Each HCC line was divided into six groups: the control group, Ang II group, irbesartan group, Ang II + irbesartan group, PD123319 (AGTR-2 blocker) group, and Ang II + PD123319 group. The corresponding treatments were administered for 48 hours, after which the adhesion between HCC cells and HUVECs in each group was measured. Compared with that in the control group, the adhesion of HCC cells to HUVECs was enhanced in the Ang II group $\left(\mathrm{P}_{\text {НмнСС97-H }}\right.$ $\left.=0.002 ; \mathrm{P}_{\text {HCCLM3 }}=0.011\right)$, and cell adhesion was decreased in the Ang II + irbesartan group but not in the Ang II + PD123319 group (Figure 2C). These results suggested that Ang II may enhance the adhesion of HCC cells through the AGTR-1 pathway. Compared with that in the control 
A

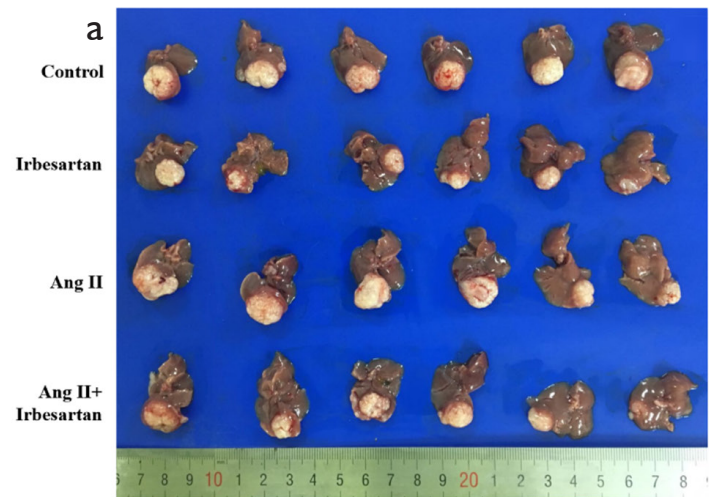

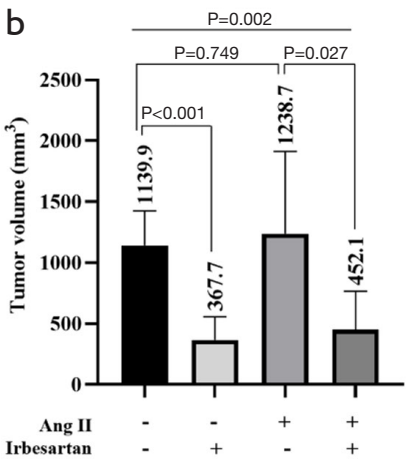

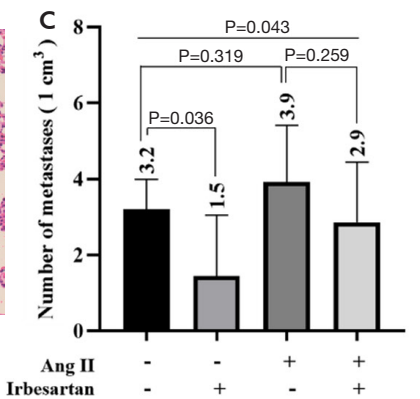

Irbesartan
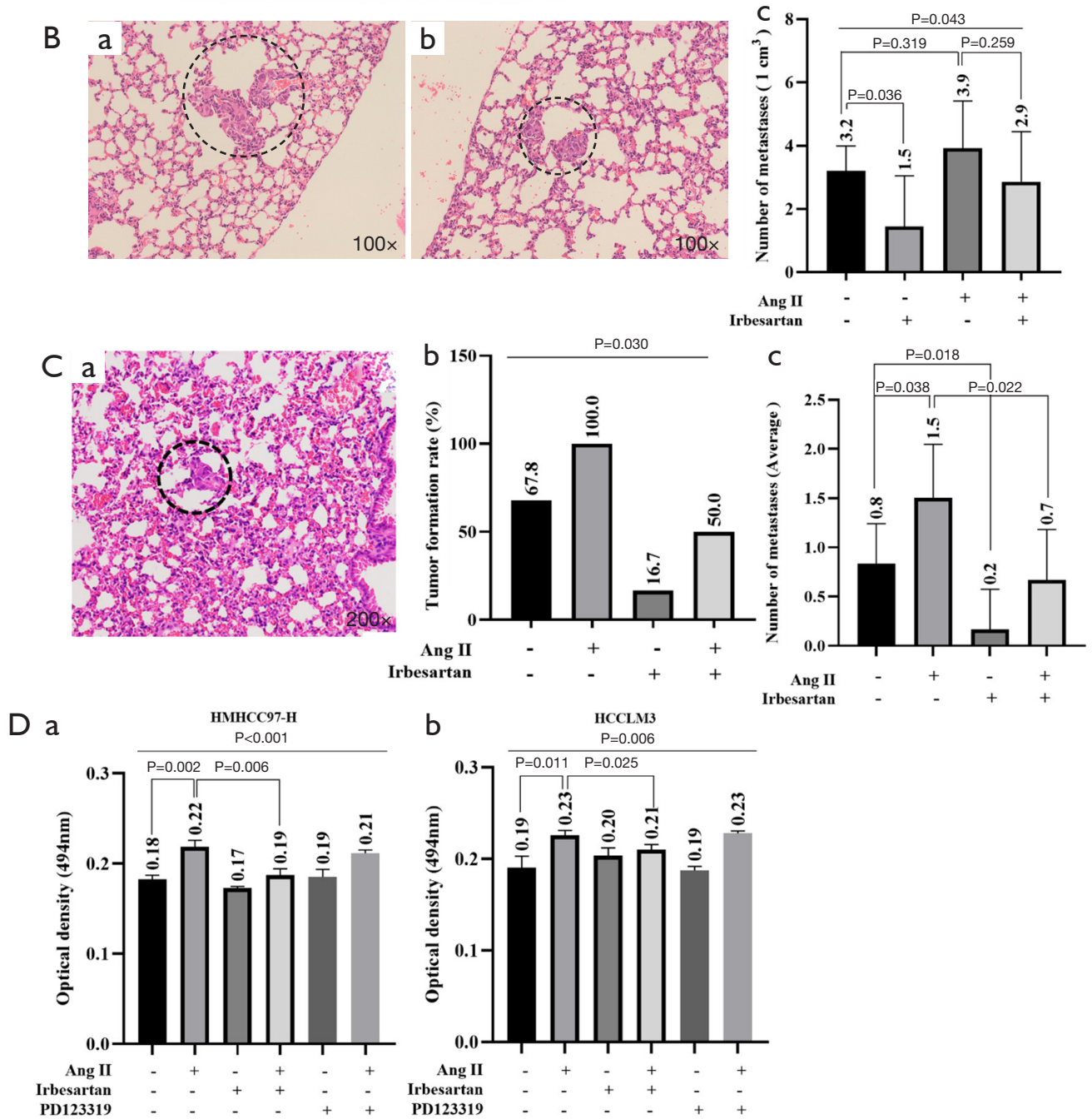

Figure 2 Irbesartan inhibited the growth and metastasis of HCC and weakened the adhesion of HCC cells to endothelial cells promoted by Ang II [metastasis foci, the dotted circle, hematoxylin-eosin (HE) staining]. (A) Irbesartan inhibited the growth of HCC in the liver $(\mathrm{P}<0.001)$, and Ang II could promote the growth of HCC but without statistical significance ( $\mathrm{P}=0.749)$. (B) Irbesartan inhibited lung metastasis of HCC in the liver $(\mathrm{P}=0.036)$, and Ang II could promote the metastasis of HCC but without statistical significance $(\mathrm{P}=0.319)$. (C) Lung metastasis model: irbesartan and Ang II affected metastasis formation in HCC (Figure b; P=0.030). Irbesartan inhibited the lung metastasis of HCC ( $\mathrm{P}=0.018)$, and Ang II promoted the metastasis of HCC ( $\mathrm{P}=0.038)$, which could be inhibited by irbesartan ( $\mathrm{P}=0.022)$. (D) Irbesartan, but not PD123319 (AGTR-2 blocker), could inhibit the adhesion of HCC cells to endothelial cells enhanced by Ang II in HMHCC97-H and HCCLM3 cells. 
Table 1 Multivariate analysis of clinicopathological parameters associated with recurrence and survival for hepatocellular carcinoma with microvascular invasion

\begin{tabular}{llll}
\hline $\begin{array}{l}\text { Clinicopathological } \\
\text { parameters }\end{array}$ & $\mathrm{HR}$ & $95 \% \mathrm{Cl}$ & $\mathrm{P}$ values \\
\hline $\begin{array}{l}\text { Time to recurrence } \\
\text { HBsAg }\end{array}$ & 0.49 & $0.28-0.86$ & 0.013 \\
$\begin{array}{l}\gamma \text {-glutamyl } \\
\text { transpeptidase }\end{array}$ & 1.67 & $1.05-2.67$ & 0.030 \\
ICAM-2 & 0.54 & $0.34-0.86$ & 0.010 \\
VCAM-1 & 2.67 & $1.68-4.25$ & 0.001 \\
$\begin{array}{l}\text { Overall survival } \\
\text { AFP }\end{array}$ & 1.76 & $1.07-2.88$ & 0.025 \\
Size & 1.07 & $1.01-1.13$ & 0.016 \\
ICAM-2 & 0.40 & $0.23-0.70$ & 0.001 \\
NRCAM & 0.59 & $0.39-0.90$ & 0.014 \\
VCAM-1 & 2.15 & $1.38-3.35$ & 0.001 \\
\hline
\end{tabular}

$\mathrm{HR}$, hazard ratios; $\mathrm{Cl}$, confidence interval; ICAM-2, Intercellular cell adhesion molecule-2; NRCAM, Neuronal cell adhesion molecule; VCAM-1, Vascular cell adhesion molecule-1.

group, no significant differences in adhesion were found in the irbesartan and PD123319 alone groups, suggesting that the two inhibitors had no significant effect on the adhesion of HCC cells or enhancement of adhesion induced by Ang II (Figure 2C). Therefore, irbesartan could inhibit the adhesion of HCC cells enhanced by Ang II, and Ang II promoted adhesion mainly through AGTR-1 and not AGTR-2.

\section{Irbesartan inbibited adbesion by reducing VCAM-1 in HCC cells}

The adhesion molecule VCAM-1 was associated with a poor prognosis of HCC with MVI and was highly expressed in HCC tissues and lung metastases

Based on the human adhesion molecule array (RayBiotech, Atlanta, Georgia), 17 adhesion molecules were screened out, and the relationship between the RNA expression of the adhesion molecules in HCC tissues and prognosis was analyzed first with the KM plotter public database (Table S2). The adhesion molecules CEACAM-1, ICAM-1, ICAM-2, NRCAM, VCAM-1 and ICAM-3 were associated with poor outcomes in HCC patients with MVI (Figure S4). Subsequently, the relationships between these 6 adhesion molecules and the prognosis for HCC patients with MVI were reanalyzed and reverified with new cases from our hospital (Figure S5). Ultimately, we found that the high expression of VCAM-1 was an independent risk factor for both recurrence (hazard ratio $=2.7 ; 95 \%$ confidence interval: $1.68-4.25 ; \mathrm{P}<0.001$ ) and survival (hazard ratio $=2.2 ; 95 \%$ confidence interval: $1.38-3.35 ; \mathrm{P}<0.001)$ in HCC patients with MVI after resection (Table 1; Table S3; Figure $3 A, B)$. Additionally, immunohistochemical staining revealed that VCAM-1 was expressed in HCC tissues and lung metastases (Figure 3C).

\section{Irbesartan could inhibit VCAM-1 in HCC cells activated by Ang II}

To verify whether VCAM-1 was regulated by Ang II in HCC cells, the HMHCC97-H and HCCLM3 lines were used and divided into 4 groups: the control group, Ang II group, irbesartan group and Ang II + irbesartan group. The protein level of VCAM-1 in each group was assessed after the corresponding treatment measures were administered for 48 hours. VCAM-1 in the Ang II group increased, and the effect was inhibited by irbesartan in both the HMHCC97-H and HCCLM3 cell lines (Figure 3D,E). These data suggested that irbesartan could inhibit VCAM-1 in HCC cells activated by Ang II. In other words, VCAM1 in HCC cells could be promoted by Ang II through the AGTR-1 pathway.

\section{The expression of VCAM-1 in HCC cells was shown to be related to adhesion in in vitro and in vivo experiments}

The expression of VCAM-1 at the RNA level in commonly used HCC cell lines was tested, and the HMHCC97-H and HCCLM3 cell lines, which have high VCAM-1 expression, were selected for the knockdown of VCAM1 by lentiviral transfection (Figure $4 A$ ). Cell adhesion experiments were performed to test the adhesion of these two cell lines with VCAM-1 knockdown. The adhesion of HMHCC97-H and HCCLM3 cells to HUVECs decreased after VCAM-1 was knocked down $\left(\mathrm{P}_{\text {НмнсС } 97-\mathrm{H}}\right.$ $=0.003 ; \mathrm{P}_{\mathrm{HCCLM} 3}=0.006 ;$ Figure $4 B-\mathrm{a}$ and $\left.\mathrm{b}\right)$. In vivo, lung metastasis model experiments showed that the number of metastases was significantly reduced after VCAM-1 knockdown $\left(\mathrm{P}_{\mathrm{HMHсC} 97-\mathrm{H}}=0.013 ; \mathrm{P}_{\text {HсCLM3 }}=0.018 ;\right.$ Figure $4 B$-c and $\mathrm{d} ; \mathrm{n}=6$ per group; no adverse events). The in vitro and in vivo results suggested that VCAM-1 expression in HCC cells was related to the adhesion of HCC cells to endothelial cells. Cells with a high expression of VCAM-1 
A
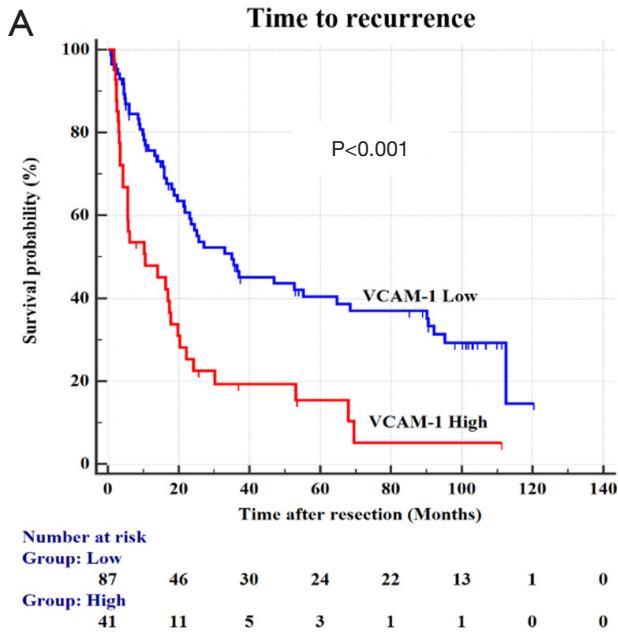

B

Overall survival

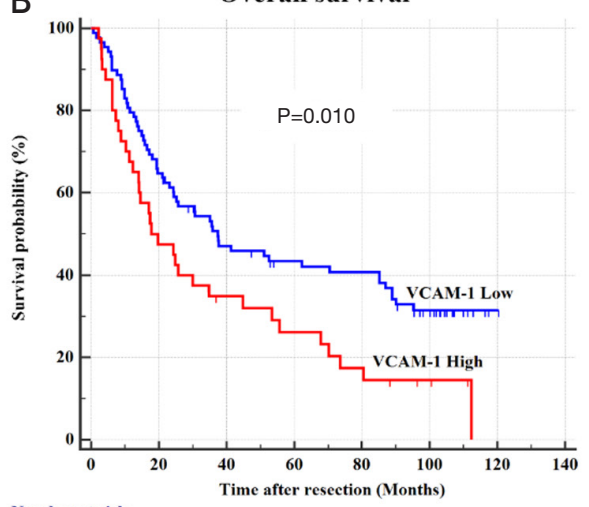

Number at risk

Group: Low

\section{C}
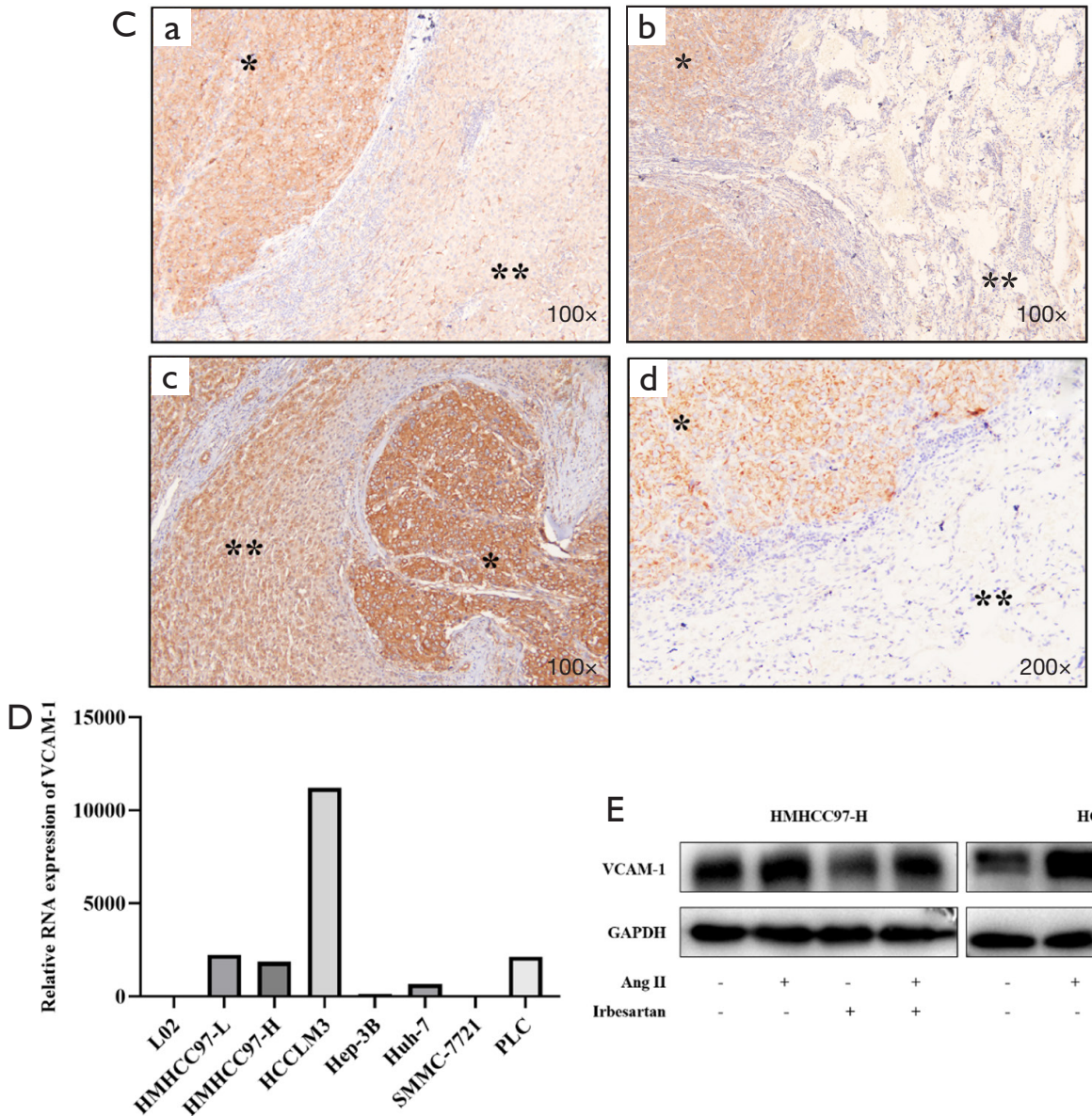

$E$

нМнСС97-H

HCCLM3

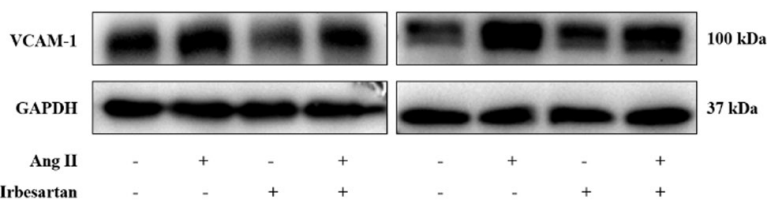

Figure 3 A high level of VCAM-1 (RNA) expression in HCC tissues was associated with a poor prognosis; this expression could be promoted by Ang II and blocked by irbesartan. Survival analysis: a high level of VCAM-1 expression was found to be an independent risk factor for recurrence (A) and survival (B) in HCC patients with microvascular invasion after resection. (C) Immunohistochemical staining of HCC tissues and lung metastases: Case 1, primary HCC in the liver (a) and lung metastases (b); Case 2, primary HCC in the liver (c) and lung metastases (d). VCAM-1 was expressed on HCC tissues and HCC cells located in metastases and at a higher level than that in peritumoral tissues; *, tumor; **, metastases. (D) Real-time PCR: VCAM-1 was expressed on HCC cell lines. (E) The expression of VCAM1 could be promoted by Ang II in HMHCC97-H and HCCLM3 cells and was inhibited by irbesartan (Ang II=0.1 $\mu M$, irbesartan $1 \mu M$ ). 

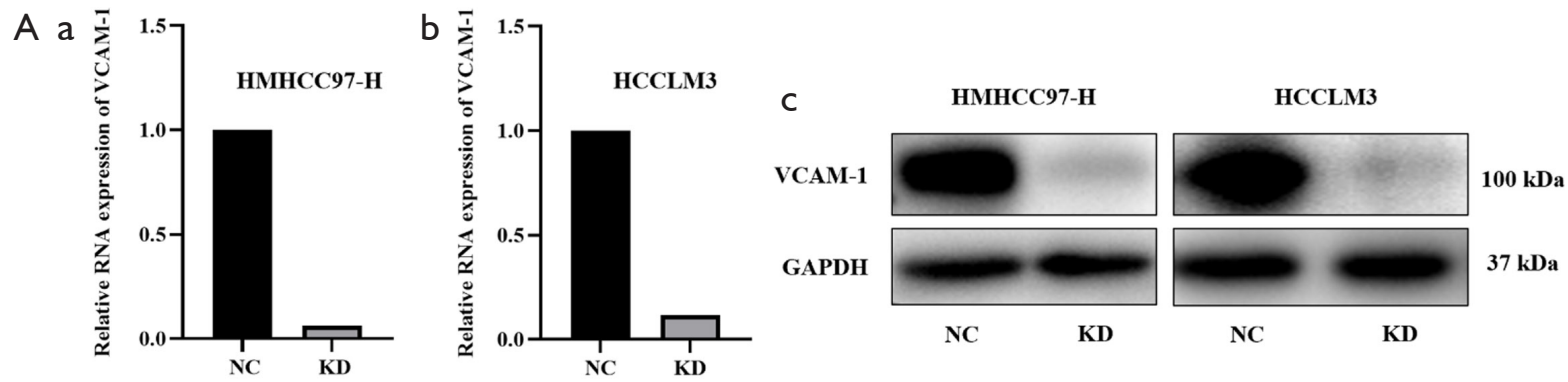

B a
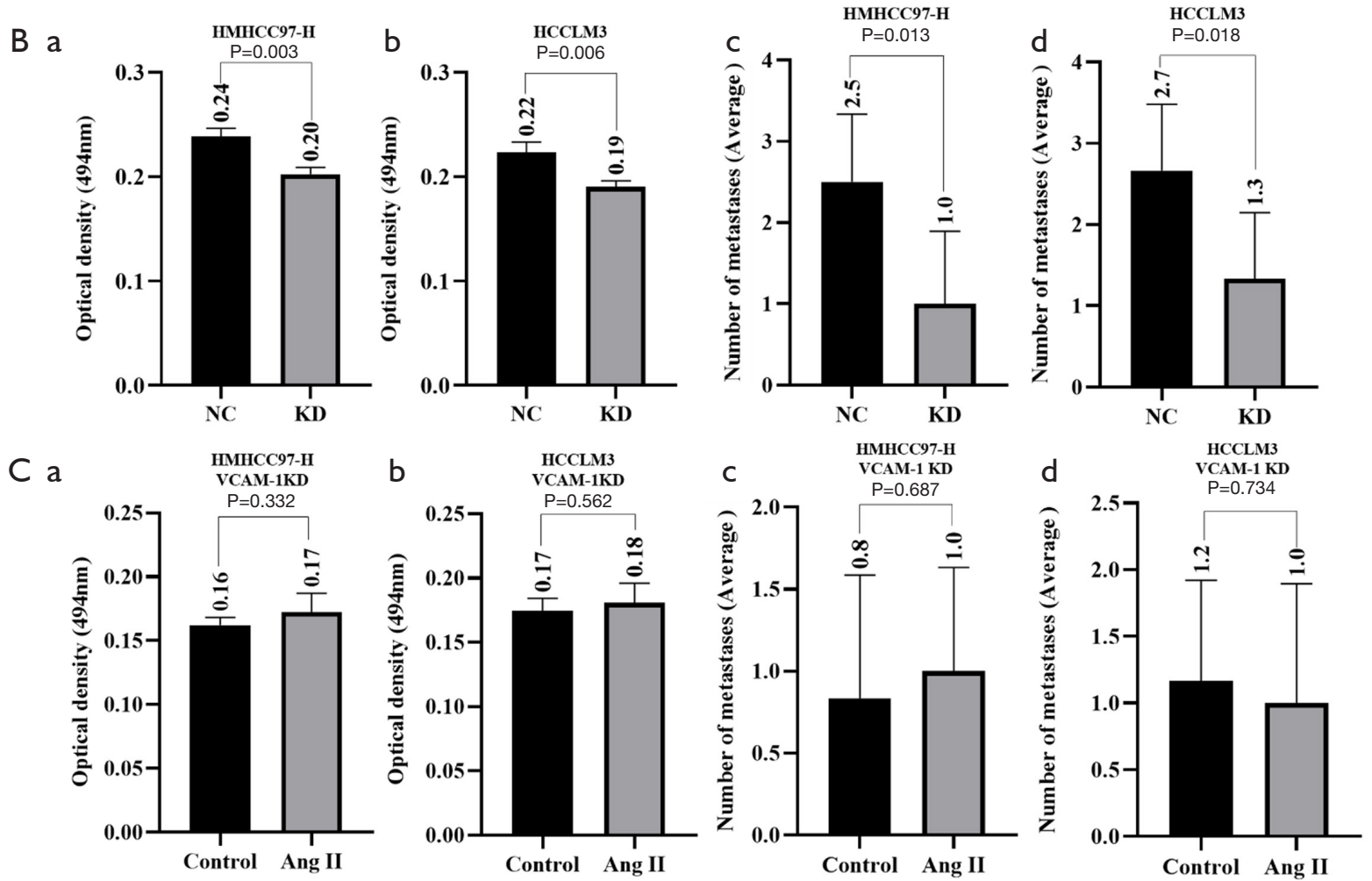

Figure 4 VCAM-1 played a role in cell adhesion. Ang II enhanced adhesion mainly by promoting the expression of VCAM-1 in HCC cells. (A) Real-time PCR and Western blotting: verification of VCAM-1 knockdown in HMHCC97-H and HCCLM3 cells. (B) Cell adhesion experiment and lung metastasis model: after VCAM-1 was knocked down in HMHCC97-H and HCCLM3 cells, the adhesion of HCC cells to HUVECs decreased (a, b), and the number of lung metastases was significantly reduced (c, d). (C) Cell adhesion experiment and lung metastasis model: no significant difference was observed in absorbance $(a, b)$ or in the number of lung metastases (c, d) between the control and Ang II groups in HMHCC97-H and HCCLM3 cells with VCAM-1 knockdown. NC, control group; KD, VCAM-1 knockdown group.

had a strong adhesion ability.

Ang II-enhanced adhesion mainly depended on VCAM1 in HCC cells in in vitro and in vivo experiments

The HMHCC97-H and HCCLM3 cell lines with knocked down VCAM-1 expression were divided into the control and Ang II groups. The cell adhesion experiments showed no significant difference in the absorbance between the control and Ang II groups in these HCC cell lines (Figure
$4 C$-a and b). Furthermore, the lung metastasis experiments demonstrated that the number of lung metastases was not significantly different between the control and Ang II groups (Figure $4 C$-c and d; $\mathrm{n}=6$ per group; no adverse events). When VCAM-1 was knocked down in HCC lines, the adhesion and metastases enhanced by Ang II were suppressed, indicating that Ang II-enhanced adhesion was mainly dependent on promoting the expression of VCAM-1 in HCC cells. 
Irbesartan inbibited VCAM-1 in HCC cells by reducing p38/MAPK phosphorylation activated by Ang II

Ang II could activate the p38/MAPK pathway in HCC cells, an effect that was blocked by its pathway inhibitor SB203580

Reports in the literature have indicated that the p38/MAPK and $\mathrm{NF}-\mathrm{\kappa B} / \mathrm{p} 65$ pathways play important roles in regulating adhesion molecules activated by Ang II in endothelial cells (42-44). Therefore, we focused on the phosphorylated protein levels of p38, p65, JNK and ERK in HMHCC97-H and HCCLM3 cells after Ang II treatment. The phosphorylation of p38 significantly increased after Ang II treatment and was blocked by the p38/MAPK pathway inhibitor SB203580 (Figure 5A,B,C).

\section{The p38/MAPK pathway was involved in the Ang II promotion of VCAM-1 in HCC cells}

The HMHCC97-H and HCCLM3 lines were divided into 4 groups: the control group, Ang II group, SB203580 group and Ang II + SB203580 group. The protein levels of VCAM-1 in each group were assessed. The Ang II group had the highest expression level of VCAM-1. When Ang II was combined with SB203580, VCAM-1 expression was significantly reduced, indicating that SB203580 could inhibit the promotion of VCAM-1 by Ang II (Figure 5D). This finding suggested that the $\mathrm{p} 38$ /MAPK phosphorylation pathway was involved in the Ang II promotion of VCAM-1 in HCC cells.

\section{The Ang II-activated p38/MAPK pathway could be inhibited by irbesartan}

The HMHCC97-H and HCCLM3 lines were divided into 6 groups: the control group, Ang II group, irbesartan group, Ang II + irbesartan group, PD123319 (AGTR2 blocker) group and Ang II + PD123319 group. The phosphorylation of $\mathrm{p} 38$ was assessed, and irbesartan was found to inhibit the phosphorylation of p38 activated by Ang II, while PD123319 had no significant effect on this phosphorylation (Figure 5E). This finding not only suggested that Ang II activated the p38/MAPK pathway mainly through the AGTR-1 receptor but also indicated that irbesartan inhibited VCAM-1 by reducing p38/MAPK phosphorylation activated by Ang II in HCC cells.

\section{Discussion}

A high risk of recurrence and metastasis and a lack of effective anti-recurrence treatments are the bottlenecks restricting surgical efficacy in HCC. Based on the previous discovery that Ang II inhibitors improve prognosis and reduce metastasis, we found that irbesartan attenuated metastasis by inhibiting Ang II-activated VCAM-1 via the p38/MAPK pathway in HCC.

Ang II inhibitors include angiotensin-converting enzyme inhibitors (ACEIs, such as captopril and enalapril) and angiotensin receptor blockers (ARBs, such as irbesartan and valsartan) (45). An ARB, irbesartan, rather than an ACEI, was used in our study because it is the most commonly used antihypertensive drug in HCC patients with primary hypertension at our hospital and serves as a selective AGTR-1 receptor blocker, facilitating analysis of the subsequent mechanism. More importantly, ACEIs, but not ARBs, have been shown to cause the accumulation of bradykinin, which has a cancer-promoting effect $(45,46)$.

In this study, the first step was to identify that AGTR1 was expressed in HCC tissues (Figure $1 A$ ). Subsequently, the HMHCC97-H and HCCLM3 cell lines, which have a relatively high expression of AGTR-1, better tumorigenicity, high invasiveness and metastasis potential, were selected for in vivo experiments (Figure 1B,C). The orthotopic liver transplantation experiment in nude mice found that irbesartan inhibited tumor growth in the liver, which is similar to observations in previous studies (14). We also found that irbesartan inhibited lung metastases promoted by Ang II (Figure 2B). The tumor size in the liver may affect the formation of lung metastases. Hence, lung metastasis experiments were performed, further verifying that Ang II promoted the lung metastasis of HCC, which could be inhibited by irbesartan (Figure 2C).

Ang II, which has a certain organ specificity in terms of its physiological synthesis, comes from angiotensin I, which is catalyzed by angiotensin-converting enzymes on lung endothelial cells and is not only a part of the lung microenvironment but also a shaping factor. Ang II has been shown to stimulate endothelial cells to express adhesion molecules, promoting CTCs to adhere to endothelial cells and form metastases; this stimulatory effect can be blocked by Ang II inhibitors $(11,13)$. Thus, we asked whether Ang II also stimulated the expression of adhesion molecules of HCC cells and promoted metastases in the same way and, if so, whether this stimulation was blocked by Ang II inhibitors. A human gene expression microarray was used to analyze Ang II-treated HMHCC97-H and HCCLM3 cells, as well as SMMC-7721 cells overexpressing the AGTR1 receptor, and we confirmed that Ang II affected the 

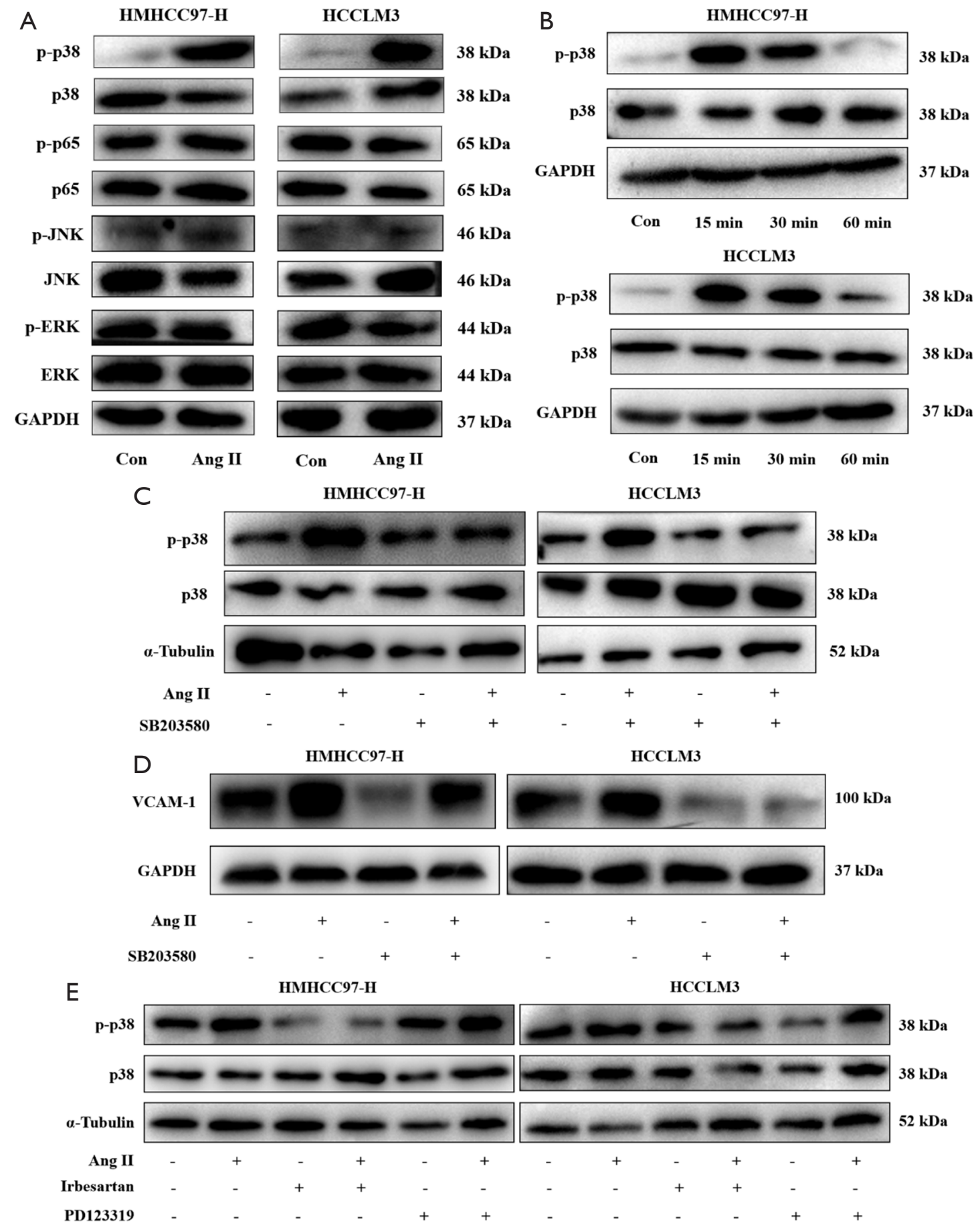

Figure 5 Irbesartan reduced p38/MAPK phosphorylation and inhibited VCAM-1 expression in HCC cells. (A) The phosphorylation of p38 was significantly increased after Ang II treatment in HMHCC97-H and HCCLM3 cells. (B) The phosphorylation of p38 activated by Ang II gradually decreased with time in HMHCC97-H and HCCLM3 cells. (C) The phosphorylation of p38 activated by Ang II could be inhibited by SB203580 (p38/MAPK pathway inhibitor) in HMHCC97-H and HCCLM3 cells. (D) The expression of VCAM-1 promoted by Ang II in HMHCC97-H and HCCLM3 cells could be inhibited by SB203580, suggesting that the p38/MAPK pathway was involved in the Ang II promotion of VCAM-1 expression in HCC cells. (E) Irbesartan, but not PD123319 (AGTR-2 inhibitor), could inhibit the phosphorylation of p38 activated by Ang II. Con, control group. 
expression of adhesion molecules in HCCs. Cell adhesion experiments indicated that Ang II could promote the adhesion of HCC cells to endothelial cells, an effect that was inhibited by irbesartan (Figure 2D).

Numerous tumor-related adhesion molecules have been identified. Therefore, we wanted to determine the key targets regulated by Ang II and irbesartan. The prerequisite for adhesion is that tumor cells have been in the circulatory system, and MVI is a direct evidence of hematogenous metastasis for HCC (24). Hence, the prognostic values of 17 adhesion molecules based on a human adhesion molecule array for HCC patients with MVI were analyzed with the KM plotter public database and clinical case data from our hospital. Ultimately, VCAM-1 was found to be an independent risk factor for recurrence and survival in HCC patients with MVI (Table 1; Figure 3A,B).

VCAM-1 is a $110-\mathrm{kDa}$ transmembrane sialic acid glycoprotein belonging to the immunoglobulin superfamily of proteins. VCAM-1 can be expressed on tumor cells, endothelial cells and immune cells and plays an important role in tumor metastasis $(47,48)$. Particularly in breast cancer, VCAM-1 participates in lymphatic metastasis, lung metastasis, bone metastasis and brain metastasis through different mechanisms (49). Therefore, VCAM-1 is a target not only for tumor therapy but also for metastasis detection by imaging (50).

However, we also wanted to determine whether VCAM1 was expressed in HCC tissues, regulated by Ang II and irbesartan, and involved in the adhesion of HCC cells to endothelial cells. Our immunohistochemical results showed that VCAM-1 was expressed in HCC tissues and lung metastases (Figure 3C). Furthermore, Western blot experiments confirmed that Ang II could promote the expression of VCAM-1 in HCC cells, which could be inhibited by irbesartan (Figure 3E). Finally, cell adhesion experiments and lung metastasis experiments confirmed that the expression of VCAM-1 in HCC cells was related to adhesion (Figure 4B). The effect of Ang II mainly depended on promoting the expression of VCAM-1 in HCC cells to enhance the adhesion of HCC cells to endothelial cells (Figure 4C).

We also wanted to know how Ang II and irbesartan affected the expression of VCAM-1 in HCC cells. In cardiovascular diseases, VCAM-1 is an important inflammatory factor in endothelial cell damage induced by Ang II through the p38/MAPK and/or NF- $\mathrm{kB} / \mathrm{p} 65$ pathways (42-44). In Ang II-treated HCC cells, the phosphorylation of p38 was enhanced most significantly, decreased gradually over time and was inhibited by its inhibitor, SB203580 (Figure $5 A, B, C$ ). These results supported the hypothesis that Ang II activates the p38/MAPK pathway in HCC cells. Furthermore, we confirmed that the p38/MAPK pathway was involved in the promotion of VCAM-1 by Ang II in HCC cells (Figure 5D). It can be easily speculated that irbesartan inhibits VCAM-1, probably because it inhibits the phosphorylation of p38 activated by Ang II. We confirmed that the phosphorylation of p38 activated by Ang II could be inhibited by irbesartan but not by PD123319 (AGTR-2 blocker; Figure $5 E$ ). Therefore, we finally speculated that Ang II could activate the p38/MAPK pathway through the AGTR-1 receptor pathway to promote VCAM-1 in HCC cells, which was blocked by irbesartan.

Our study possessed several limitations. First, the drug doses used in the cytology and animal experiments mainly relied on previous studies and were not directly determined. Second, cytology and animal experiments on VCAM-1 were primarily performed to establish knockdown HCC lines, which should be verified by the overexpression of VCAM-1 in HCC lines. Third, the results of the study should be verified with more HCC cell lines.

In conclusion, we found that the Ang II inhibitor irbesartan blocked the binding of Ang II and AGTR-1, reduced the phosphorylation of the p38/MAPK pathway activated by Ang II, inhibited VCAM-1 expression in HCC cells, weakened the adhesion of HCC cells to endothelial cells and attenuated metastasis. The high expression level of VCAM-1 in HCC tissues is an independent risk factor for the poor prognosis of HCC patients with MVI.

\section{Acknowledgments}

Funding: This work was supported by the Leading Investigator Program of Shanghai municipal government (17XD1401100), the National Key Basic Research Program (973 Program; 2015CB554005) from the Ministry of Science and Technology of China, and the National Natural Science Foundation of China (81672326).

\section{Footnote}

Reporting Checklist: The authors have completed the ARRIVE reporting checklist. Available at http://dx.doi. org/10.21037/atm-20-5293

Data Sharing Statement: Available at http://dx.doi. org/10.21037/atm-20-5293 
Conflicts of Interest: All authors have completed the ICMJE uniform disclosure form (available at http://dx.doi. org/10.21037/atm-20-5293). The authors have no conflicts of interest to declare.

Ethical Statement: The authors are accountable for all aspects of the work in ensuring that questions related to the accuracy or integrity of any part of the work are appropriately investigated and resolved. It was approved by the Clinical Research Ethics Committee of Zhongshan Hospital, Fudan University, Shanghai, China (Approval No.: B2012-010) and the individual consent for this retrospective analysis was waived. The animal experiments were approved by the Shanghai Medical Experimental Animal Care Committee (Approval date, December 2017). All procedures were performed following the Guide for the Care and Use of Laboratory Animals and complied with institutional ethical guidelines.

Open Access Statement: This is an Open Access article distributed in accordance with the Creative Commons Attribution-NonCommercial-NoDerivs 4.0 International License (CC BY-NC-ND 4.0), which permits the noncommercial replication and distribution of the article with the strict proviso that no changes or edits are made and the original work is properly cited (including links to both the formal publication through the relevant DOI and the license). See: https://creativecommons.org/licenses/by-nc-nd/4.0/.

\section{References}

1. Villanueva A. Hepatocellular Carcinoma. N Engl J Med 2019;380:1450-62.

2. Forner A, Reig M, Bruix J. Hepatocellular carcinoma. Lancet 2018;391:1301-14.

3. Singal AG, Lampertico P, Nahon P. Epidemiology and surveillance for hepatocellular carcinoma: New trends. J Hepatol 2020;72:250-61.

4. Siegel RL, Miller KD, Jemal A. Cancer statistics, 2020. CA Cancer J Clin 2020;70:7-30.

5. Yang JD, Hainaut P, Gores GJ, et al. A global view of hepatocellular carcinoma: trends, risk, prevention and management. Nat Rev Gastroenterol Hepatol 2019;16:589-604.

6. Inarrairaegui M, Melero I, Sangro B. Immunotherapy of Hepatocellular Carcinoma: Facts and Hopes. Clin Cancer Res 2018;24:1518-24.

7. Pinter M, Peck-Radosavljevic M. Review article: systemic treatment of hepatocellular carcinoma. Aliment Pharmacol Ther 2018;48:598-609.

8. Rosenthal T, Gavras I. Renin-Angiotensin Inhibition in Combating Malignancy: A Review. Anticancer Res 2019;39:4597-602.

9. Li XY, Sun JF, Hu SQ. The renin-angiotensin system blockers as adjunctive therapy for cancer: a meta-analysis of survival outcome. Eur Rev Med Pharmacol Sci 2017;21:1375-83.

10. Barone M, Viggiani MT, Losurdo G, et al. Systematic review: Renin-angiotensin system inhibitors in chemoprevention of hepatocellular carcinoma. World J Gastroenterol 2019;25:2524-38.

11. Ishikane $S$, Takahashi-Yanaga $F$. The role of angiotensin II in cancer metastasis: Potential of renin-angiotensin system blockade as a treatment for cancer metastasis. Biochem Pharmacol 2018;151:96-103.

12. Pinter $M$, Jain RK. Targeting the renin-angiotensin system to improve cancer treatment: Implications for immunotherapy. Sci Transl Med 2017;9:eaan5616.

13. Ishikane S, Hosoda H, Nojiri T, et al. Angiotensin II promotes pulmonary metastasis of melanoma through the activation of adhesion molecules in vascular endothelial cells. Biochem Pharmacol 2018;154:136-47.

14. Ji Y, Wang Z, Li Z, et al. Angiotensin II Enhances Proliferation and Inflammation through AT1/PKC/NFkappaB Signaling Pathway in Hepatocellular Carcinoma Cells. Cell Physiol Biochem 2016;39:13-32.

15. Ji Y, Wang $Z$, Li $Z$, et al. Angiotensin II induces angiogenic factors production partly via AT1/JAK2/ STAT3/SOCS3 signaling pathway in MHCC97H cells. Cell Physiol Biochem 2012;29:863-74.

16. Qi M, Zhou Y, Liu J, et al. AngII induces HepG2 cells to activate epithelial-mesenchymal transition. Exp Ther Med 2018;16:3471-7.

17. Yoshiji H, Noguchi R, Ikenaka Y, et al. Impact of reninangiotensin system in hepatocellular carcinoma. Curr Cancer Drug Targets 2011;11:431-41.

18. Facciorusso A, Del Prete V, Crucinio N, et al. Angiotensin receptor blockers improve survival outcomes after radiofrequency ablation in hepatocarcinoma patients. J Gastroenterol Hepatol 2015;30:1643-50.

19. Pinter M, Weinmann A, Worns MA, et al. Use of inhibitors of the renin-angiotensin system is associated with longer survival in patients with hepatocellular carcinoma. United European Gastroenterol J 2017;5:987-96.

20. Kaibori M, Ishizaki M, Matsui K, et al. Evaluation of metabolic factors on the prognosis of patients undergoing 
resection of hepatocellular carcinoma. J Gastroenterol Hepatol 2011;26:536-43.

21. Yoshiji H, Noguchi R, Ikenaka Y, et al. Combination of branched-chain amino acids and angiotensin-converting enzyme inhibitor suppresses the cumulative recurrence of hepatocellular carcinoma: a randomized control trial. Oncol Rep 2011;26:1547-53.

22. Yoshiji H, Noguchi R, Toyohara M, et al. Combination of vitamin $\mathrm{K} 2$ and angiotensin-converting enzyme inhibitor ameliorates cumulative recurrence of hepatocellular carcinoma. J Hepatol 2009;51:315-21.

23. Feng LH, Sun HC, Zhu XD, et al. Renin-angiotensin inhibitors were associated with improving outcomes of hepatocellular carcinoma with primary hypertension after hepatectomy. Ann Transl Med 2019;7:739.

24. Cong WM, Bu H, Chen J, et al. Practice guidelines for the pathological diagnosis of primary liver cancer: 2015 update. World J Gastroenterol 2016;22:9279-87.

25. Ahn JC, Teng PC, Chen PJ, et al. Detection of circulating tumor cells and their implications as a novel biomarker for diagnosis, prognostication, and therapeutic monitoring in hepatocellular carcinoma. Hepatology 2020.

26. Honn KV, Tang DG. Adhesion molecules and tumor cell interaction with endothelium and subendothelial matrix. Cancer Metastasis Rev 1992;11:353-75.

27. Zhang YY, Kong LQ, Zhu XD, et al. CD31 regulates metastasis by inducing epithelial-mesenchymal transition in hepatocellular carcinoma via the ITGB1-FAK-Akt signaling pathway. Cancer Lett 2018;429:29-40.

28. Shi WK, Zhu XD, Wang CH, et al. PFKFB3 blockade inhibits hepatocellular carcinoma growth by impairing DNA repair through AKT. Cell Death Dis 2018;9:428.

29. Janhavi P, Divyashree S, Sanjailal KP, et al. DoseCal: a virtual calculator for dosage conversion between human and different animal species. Arch Physiol Biochem 2019:1-5. [Epub ahead of print].

30. Wang YX, Martin-McNulty B, da Cunha V, et al. Fasudil, a Rho-kinase inhibitor, attenuates angiotensin II-induced abdominal aortic aneurysm in apolipoprotein E-deficient mice by inhibiting apoptosis and proteolysis. Circulation 2005;111:2219-26.

31. Du N, Feng J, Hu LJ, et al. Angiotensin II receptor type 1 blockers suppress the cell proliferation effects of angiotensin II in breast cancer cells by inhibiting AT1R signaling. Oncol Rep 2012;27:1893-903.

32. Nguyen L, Ager EI, Neo J, et al. Regulation of colorectal cancer cell epithelial to mesenchymal transition by the renin angiotensin system. J Gastroenterol Hepatol
2016;31:1773-82.

33. Li B, Wang Z, Hu Z, et al. P38 MAPK Signaling Pathway Mediates Angiotensin II-Induced miR143/145 Gene Cluster Downregulation during Aortic Dissection Formation. Ann Vasc Surg 2017;40:262-73.

34. Wang Y, Zhang X, Gao L, et al. Cortistatin exerts antiproliferation and antimigration effects in vascular smooth muscle cells stimulated by Ang II through suppressing ERK1/2, p38 MAPK, JNK and ERK5 signaling pathways. Ann Transl Med 2019;7:561.

35. Pham H, Chong B, Vincenti R, et al. Ang II and EGF synergistically induce COX-2 expression via CREB in intestinal epithelial cells. J Cell Physiol 2008;214:96-109.

36. Nagy A, Lanczky A, Menyhart O, et al. Validation of miRNA prognostic power in hepatocellular carcinoma using expression data of independent datasets. Sci Rep 2018;8:9227.

37. Available online: http://www.r-project.org/.

38. Available online: https://www.medcalc.org/index.php.

39. Available online: https://cran.r-project.org/web/packages/ survminer/index.html.

40. Tian J, Tang ZY, Ye SL, et al. New human hepatocellular carcinoma (HCC) cell line with highly metastatic potential (MHCC97) and its expressions of the factors associated with metastasis. Br J Cancer 1999;81:814-21.

41. Li Y, Tian B, Yang J, et al. Stepwise metastatic human hepatocellular carcinoma cell model system with multiple metastatic potentials established through consecutive in vivo selection and studies on metastatic characteristics. J Cancer Res Clin Oncol 2004;130:460-8.

42. Song KH, Park JH, Jo I, et al. Telmisartan attenuates hyperglycemia-exacerbated VCAM-1 expression and monocytes adhesion in TNFalpha-stimulated endothelial cells by inhibiting IKKbeta expression. Vascul Pharmacol 2016;78:43-52.

43. Liang B, Wang X, Zhang N, et al. Angiotensin-(1-7) Attenuates Angiotensin II-Induced ICAM-1, VCAM-1, and MCP-1 Expression via the MAS Receptor Through Suppression of P38 and NF-kappaB Pathways in HUVECs. Cell Physiol Biochem 2015;35:2472-82.

44. Zhang F, Ren J, Chan K, et al. Angiotensin-(1-7) regulates Angiotensin II-induced VCAM-1 expression on vascular endothelial cells. Biochem Biophys Res Commun 2013;430:642-6.

45. Messerli FH, Bangalore S, Bavishi C, et al. AngiotensinConverting Enzyme Inhibitors in Hypertension: To Use or Not to Use? J Am Coll Cardiol 2018;71:1474-82.

46. Wang G, Sun J, Liu G, et al. Bradykinin Promotes Cell 
Proliferation, Migration, Invasion, and Tumor Growth of Gastric Cancer Through ERK Signaling Pathway. J Cell Biochem 2017;118:4444-53.

47. Schlesinger M, Bendas G. Vascular cell adhesion molecule-1 (VCAM-1)--an increasing insight into its role in tumorigenicity and metastasis. Int J Cancer 2015;136:2504-14.

48. Wieland E, Rodriguez-Vita J, Liebler SS, et al. Endothelial Notch1 Activity Facilitates Metastasis. Cancer Cell

Cite this article as: Feng LH, Sun HC, Zhu XD, Zhang SZ, Li XL, Li KS, Liu XF, Lei M, Li Y, Tang ZY. Irbesartan inhibits metastasis by interrupting the adherence of tumor cell to endothelial cell induced by angiotensin II in hepatocellular carcinoma. Ann Transl Med 2021;9(3):207. doi: 10.21037/atm20-5293
2017;31:355-67.

49. Sharma R, Sharma R, Khaket TP, et al. Breast cancer metastasis: Putative therapeutic role of vascular cell adhesion molecule-1. Cell Oncol (Dordr) 2017;40:199-208.

50. Cheng VWT, Soto MS, Khrapitchev AA, et al. VCAM-1targeted MRI Enables Detection of Brain Micrometastases from Different Primary Tumors. Clin Cancer Res 2019;25:533-43. 


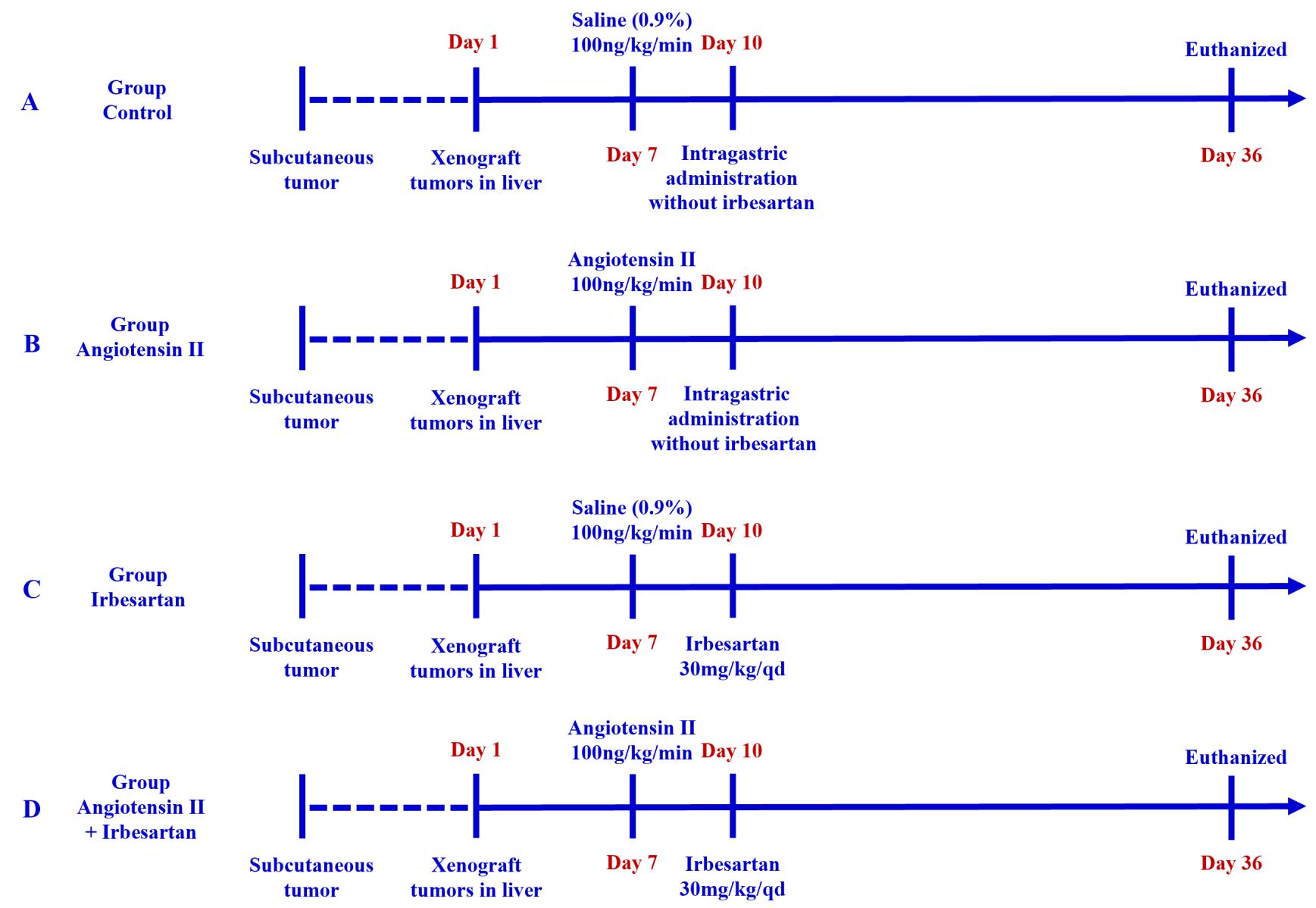

Figure S1 The groups and time axes of animal experiments (Orthotopic tumor xenograft model). 


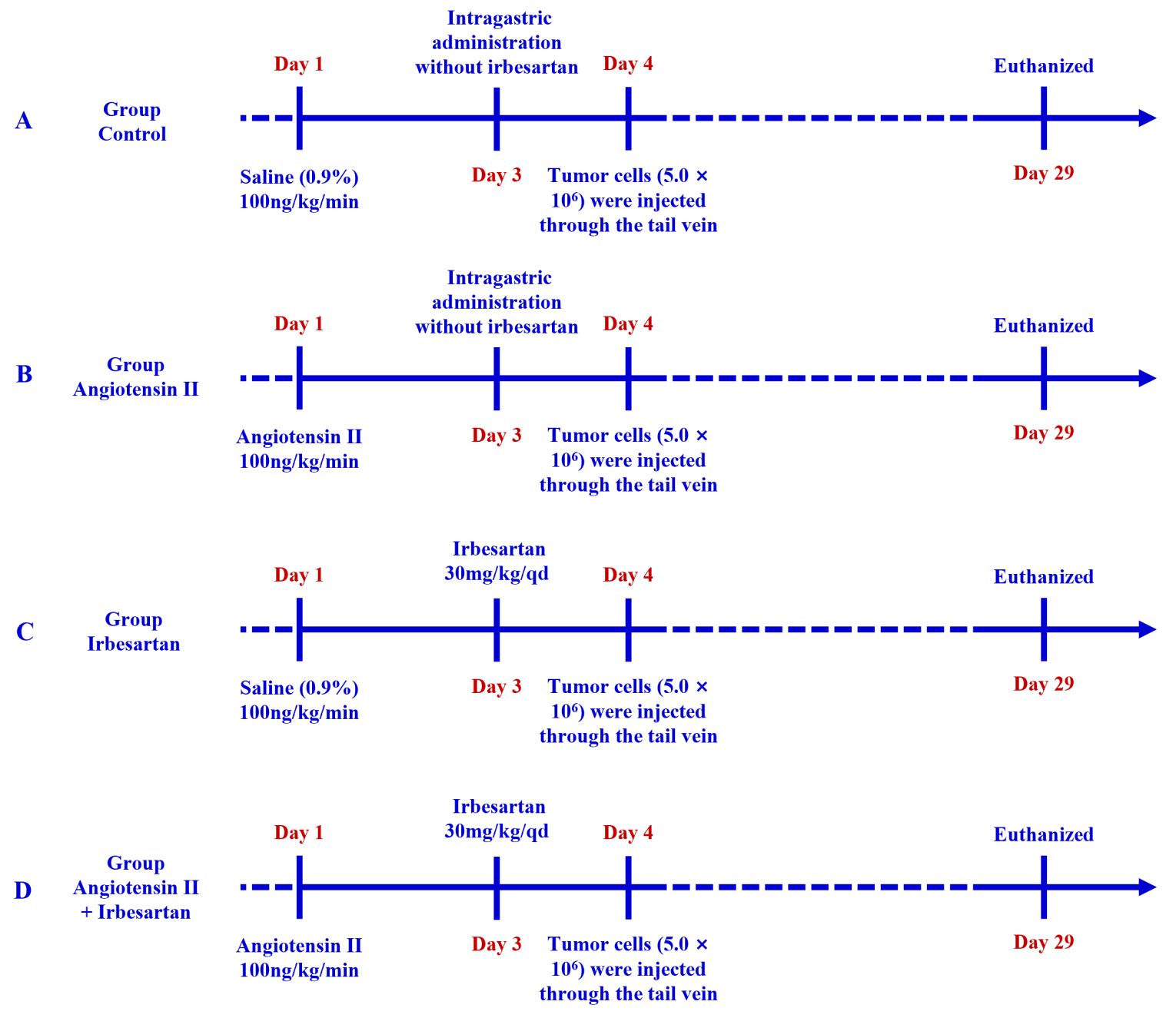

Figure S2 The groups and time axes of animal experiments (Lung metastasis model). 
A

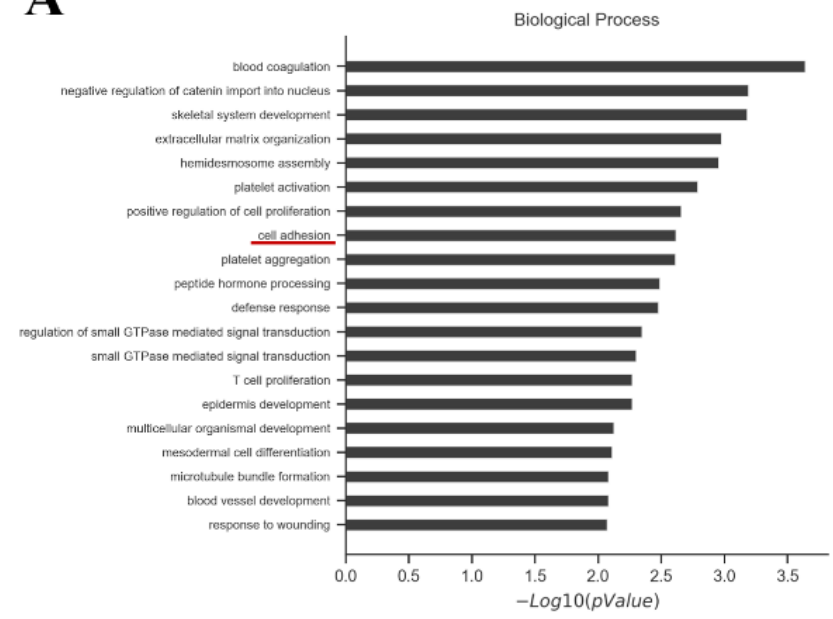

C

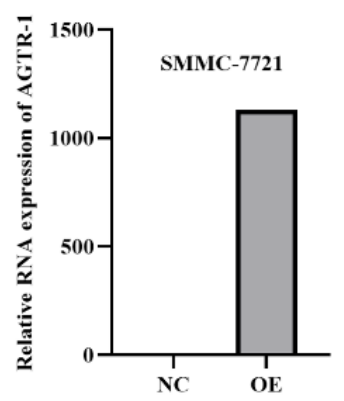

\section{B}

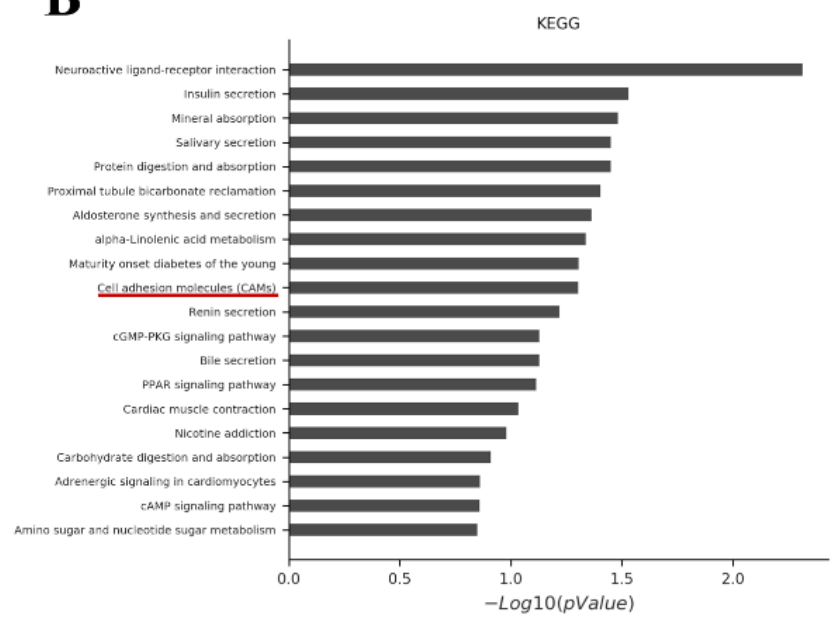

D

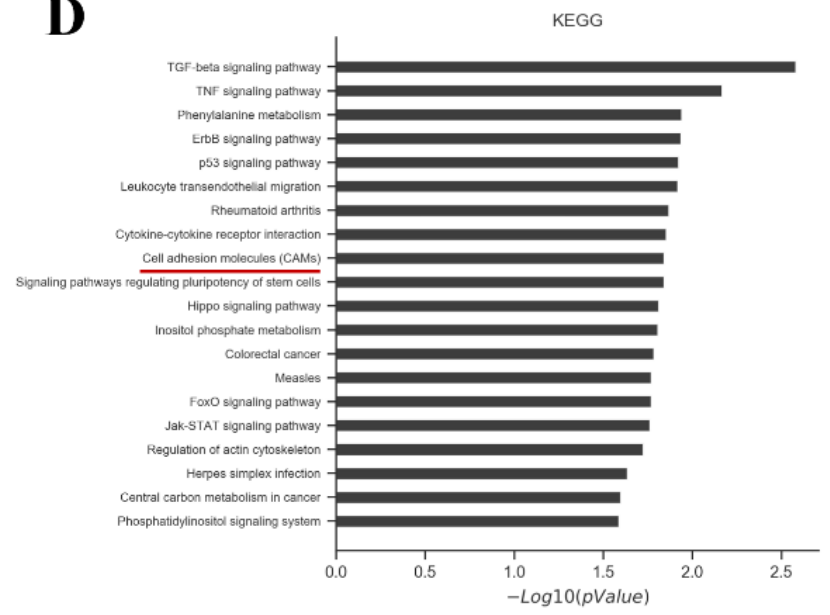

Figure S3 Human gene expression microarray: Ang II could affect the expression of adhesion molecules in HCC cells. (A) Biological behavior analysis on Ang II-treated HMHCC97-H cells and control HMHCC97-H cells. (B) Kyoto Encyclopedia of Genes and Genomes (KEGG) analysis on Ang II-treated HCCLM3 cells and control HCCLM3 cells. (C) Real-time PCR and Western blot: verification of AGTR-1 overexpression in SMMC-7721 cells. (D) KEGG analysis on SMMC-7721-AGTR-1-overexpressed cells and SMMC-7721Control cells. NC, control group; OE, AGTR-1 overexpression group. 
A

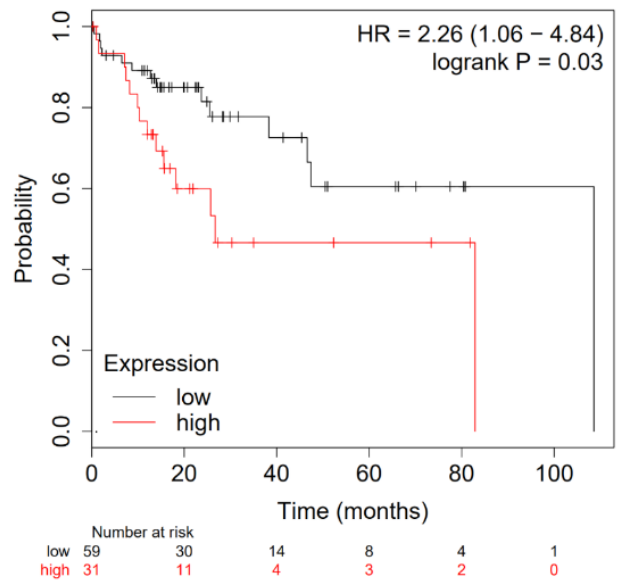

C ICAM2 (3384)

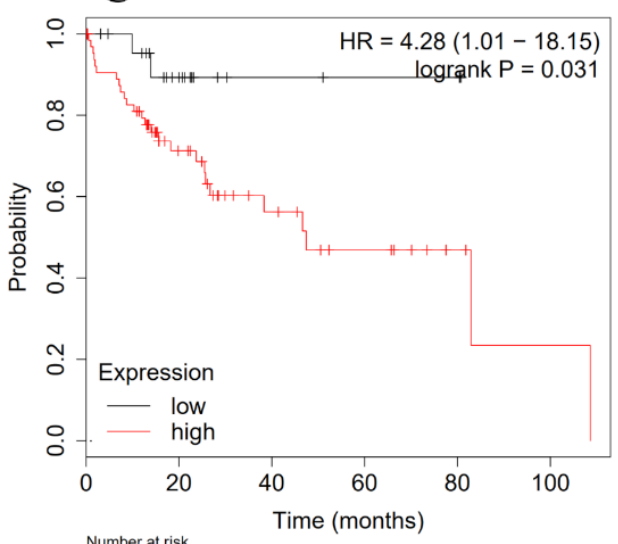

$\begin{array}{lll} & \text { Number at risk } \\ \text { low } & 25 & 12 \\ \text { high } & 65 & 29\end{array}$

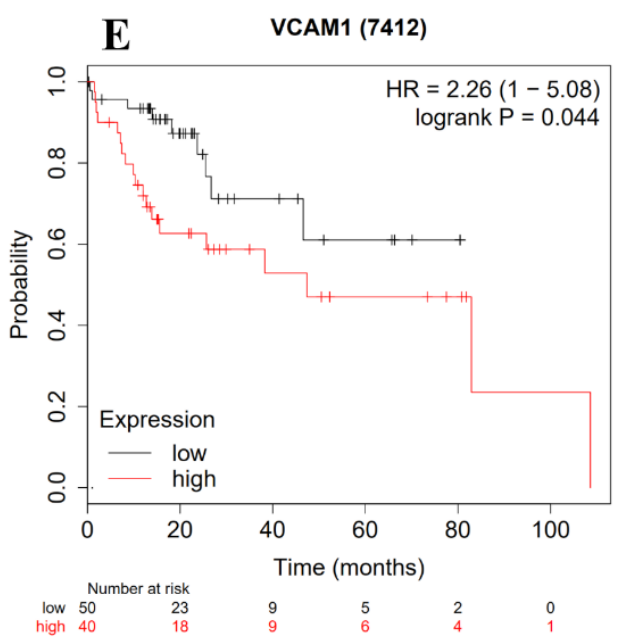

B

ICAM1 (3383)
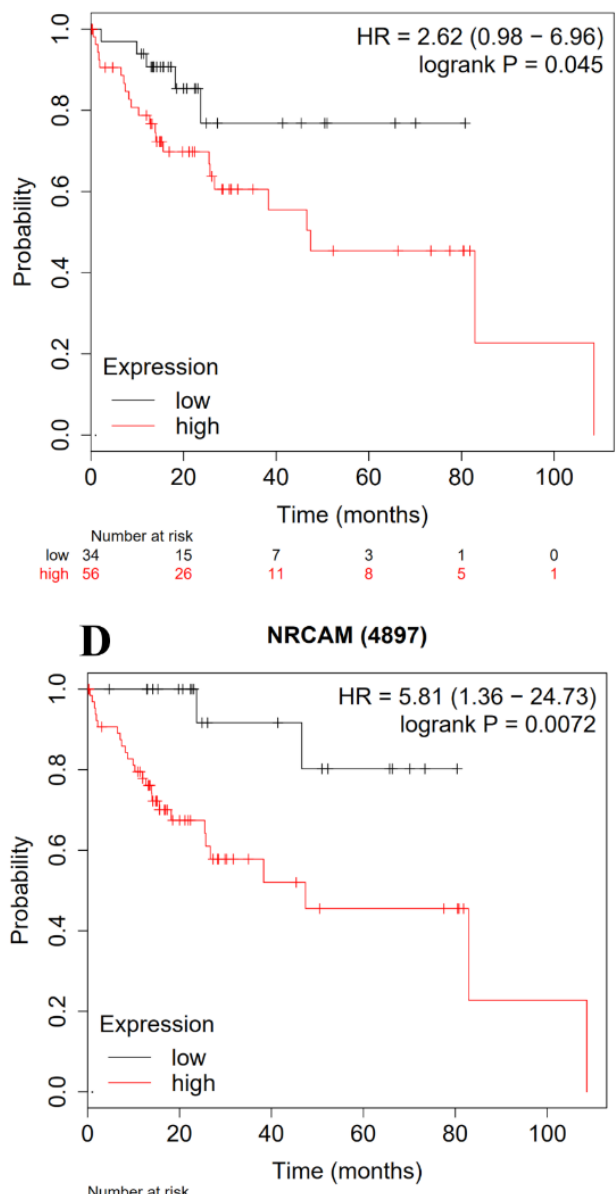

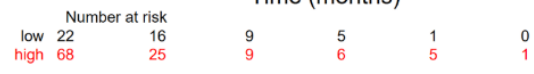

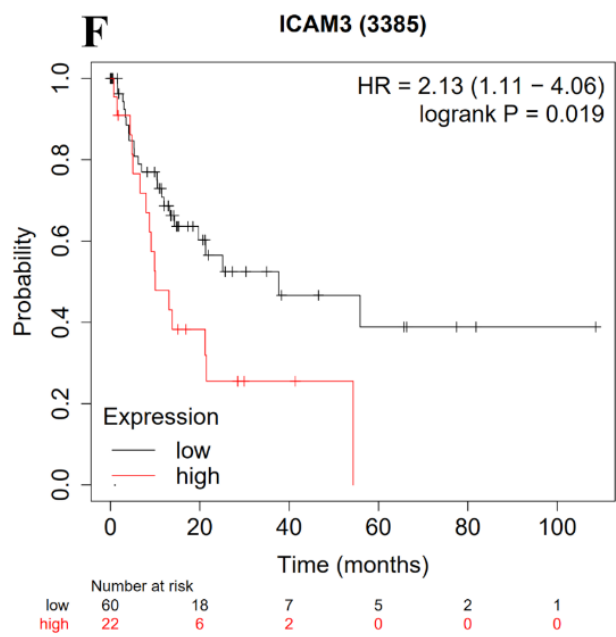

Figure S4 The relationships between the expression of six adhesion molecules in HCC tissues and prognosis in HCC patients with microvascular invasion (KM-Plotter public database, n=90). (A) CEACAM-1, overall survival; (B) ICAM-1, overall survival; (C) ICAM-2, overall survival; (D) NRCAM, overall survival; (E) VCAM-1, overall survival; (F) ICAM-3, recurrence. 

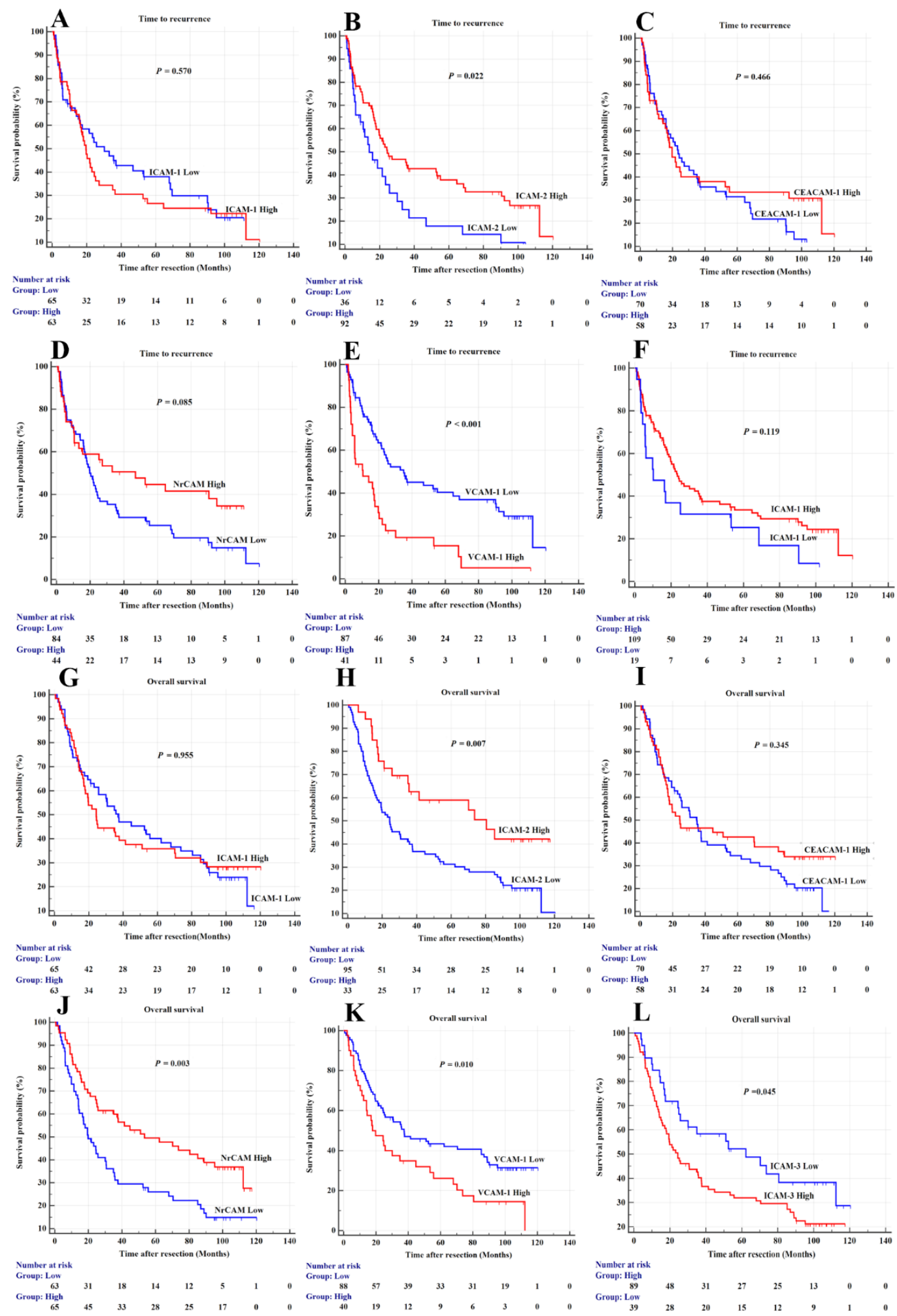

Figure S5 The relationships between the expression of five adhesion molecules in HCC tissues and overall survival in HCC patients with microvascular invasion (clinical cases from our hospital, n=128). Recurrence: (A) CEACAM-1; (B) ICAM-1; (C) ICAM-2; (D) NRCAM; (E) VCAM-1; (F) ICAM-3. Overall survival: (G) CEACAM-1; (H) ICAM-1; (I) ICAM-2; (J) NRCAM; (K) VCAM-1; (L) ICAM-3. 
Table S1 PCR primers and sequences

\begin{tabular}{lll}
\hline Name & Primer & Sequences $\left(5^{\prime} \rightarrow 3^{\prime}\right)$ \\
\hline AGTR-1 & Forward & CACTGGCTGACTTATGCTTTTT \\
AGTR-1 & Reverse & TAGAAACACACTAGCGTACAGG \\
VCAM-1 & Forward & CAGGCTGGAGATAGACTTACTG \\
VCAM-1 & Reverse & CCTCAATGACAGGAGTAAAGGT \\
CEACAM-1 & Forward & CCACAGTCAAGACGATCATAGT \\
CEACAM-1 & Reverse & TCATCTTGTTAGGTGGGTCATT \\
ICAM-1 & Forward & TGCAAGAAGATAGCCAACCAAT \\
ICAM-1 & Reverse & GTACACGGTGAGGAAGGTTTTA \\
ICAM-2 & Forward & ATGAGACTCTGCACTATGAGAC \\
ICAM-2 & Reverse & GCTGAGTGTTTGTGAAAGATGT \\
NRCAM & Forward & CGGAGCTGCAGTTCTAATAAC \\
NRCAM & Reverse & TGCAGGGAAGTACTAAAGACTG
\end{tabular}

AGTR-1, angiotensin II type 1 receptor; VCAM-1, vascular cell adhesion molecule-1; CEACAM-1, CEA cell adhesion molecule-1; ICAM-1, intercellular cell adhesion molecule-1; ICAM-2, intercellular cell adhesion molecule-2; NRCAM, neuronal cell adhesion molecule.

Table S2 Seventeen adhesion molecules and prognosis of hepatocellular carcinoma with microvascular invasion after resection (KM-plotter public database)

\begin{tabular}{|c|c|c|c|c|}
\hline Number & Adhesion molecules & Abbreviation & OS $(n=90)$ & RFS $(n=90)$ \\
\hline 2 & Basal Cell Adhesion Molecule & BCAM & - & - \\
\hline 3 & CEA cell adhesion molecule- 1 & CEACAM-1 & $\uparrow$ & $\downarrow$ \\
\hline 4 & Epithelial Cell Adhesion Molecule & EpCAM & $\downarrow$ & - \\
\hline 6 & Intercellular cell adhesion molecule-1 & ICAM-1 & $\uparrow$ & - \\
\hline 7 & Intercellular cell adhesion molecule-2 & ICAM-2 & $\uparrow$ & - \\
\hline 8 & Intercellular cell adhesion molecule-3 & ICAM-3 & - & $\uparrow$ \\
\hline 9 & Neuronal cell adhesion molecule- 1 & NCAM-1 & - & - \\
\hline 12 & Platelet endothelial cell adhesion molecule-1 & PECAM-1 & - & $\downarrow$ \\
\hline 13 & Endothelial selectin & E- Selectin & - & - \\
\hline 14 & Leukocyte selectin & L-Selectin & - & - \\
\hline 15 & Platelet selectin & P-Selectin & - & - \\
\hline 16 & Vascular cell adhesion molecule-1 & VCAM-1 & $\uparrow$ & - \\
\hline 17 & Vascular endothelial cadherin & VE-Cadherin & $\downarrow$ & - \\
\hline
\end{tabular}

OS, overall survival; RFS, recurrence free survival; MVI, microvascular invasion; "“”, High expression is associated with poor prognosis; " $\downarrow$ ”, Low expression is associated with poor prognosis; "-", no difference in prognosis. 
Table S3 Univariate analysis of clinicopathological parameters associated with recurrence and survival in hepatocellular carcinoma patients with microvascular invasion

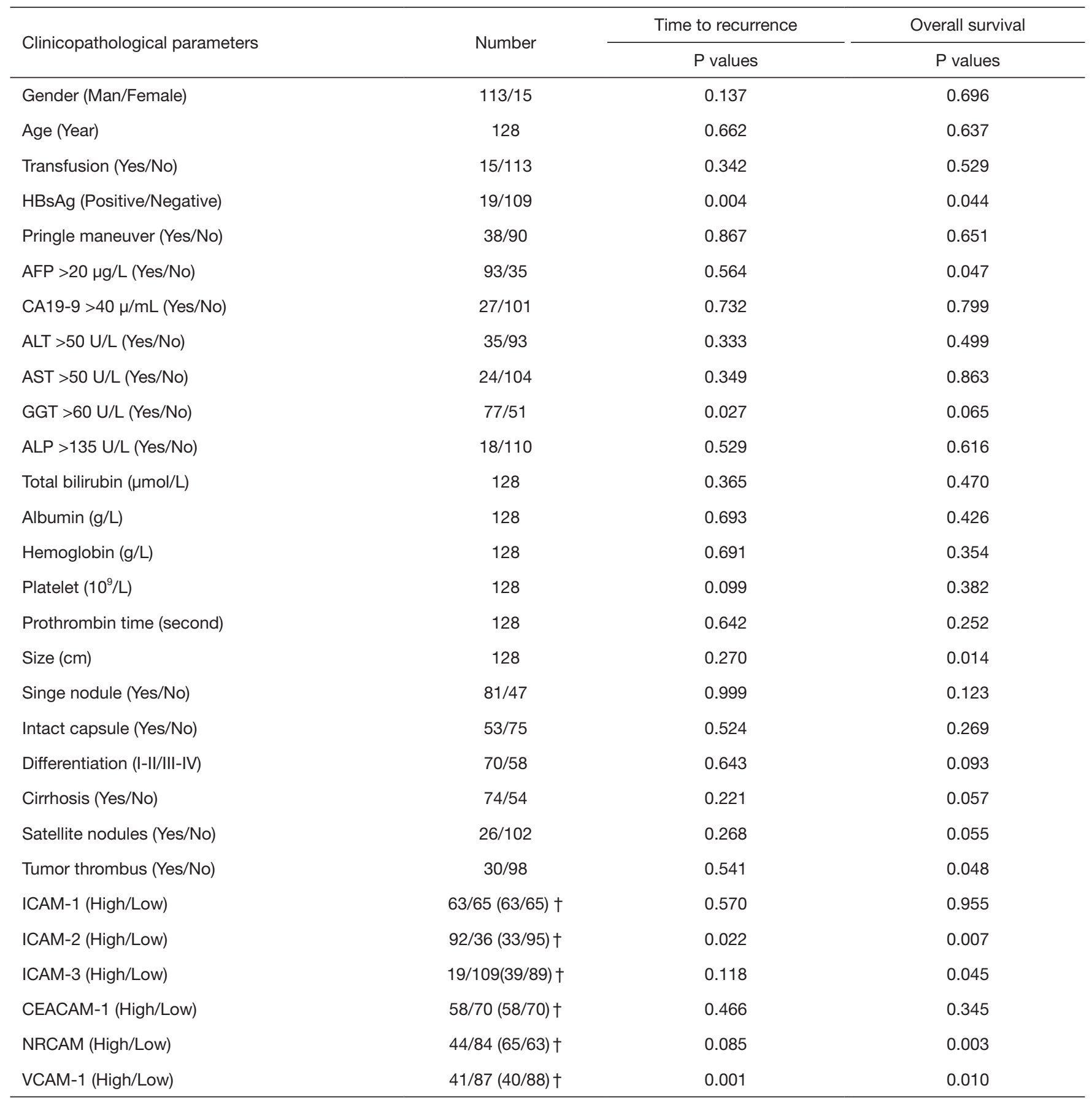

†, group of overall survival. ALT, alanine transaminase; AST, aspartate aminotransferase; ALP, alkaline phosphatase; GGT, $\gamma$-glutamyl transpeptidase; ICAM-1, Intercellular cell adhesion molecule-1; ICAM-2, Intercellular cell adhesion molecule-2; ICAM-3, Intercellular cell adhesion molecule-3; CEACAM-1, CEA cell adhesion molecule-1; NRCAM, Neuronal cell adhesion molecule; VCAM-1, Vascular cell adhesion molecule-1. 